\title{
Room-Temperature Cu(II) Radical-Triggered Alkyne C-H Activation
}

Jack Devonport, Lauren Sully, Athanassios K. Boudalis, Storm Hassell-Hart, Matthew C. Leech, Kevin Lam, Alaa Abdul-Sada, Graham J. Tizzard, Simon J. Coles, John Spencer,* Alfredo Vargas,* and George E. Kostakis*

Cite This: https://doi.org/10.1021/jacsau.1c00310

Read Online

ABSTRACT: A dimeric $\mathrm{Cu}(\mathrm{II})$ complex $\left[\mathrm{Cu}(\mathrm{II})_{2} \mathrm{~L}_{2}\left(\mu_{2}-\mathrm{Cl}\right) \mathrm{Cl}\right]$ (1) built from an asymmetric tridentate ligand (2- (( (2aminocyclohexyl)imino)methyl)-4,6-di-tert-butylphenol) and weakly coordinating anions has been synthesized and structurally characterized. In dichloromethane solution, 1 exists in a monomeric $[\mathrm{Cu}(\mathrm{II}) \mathrm{LCl}]\left(\mathbf{1}^{\prime}\right)(85 \%)$-dimeric $(\mathbf{1})(15 \%)$ equilibrium, and cyclic voltammetry $(\mathrm{CV})$ and electron paramagnetic resonance (EPR) studies indicate structural stability and redox retention. Addition of phenylacetylene to the $\mathrm{CH}_{2} \mathrm{Cl}_{2}$ solution populates $\mathbf{1}^{\prime}$ and leads to the formation of a transient radical species. Theoretical studies support this notion and show that the

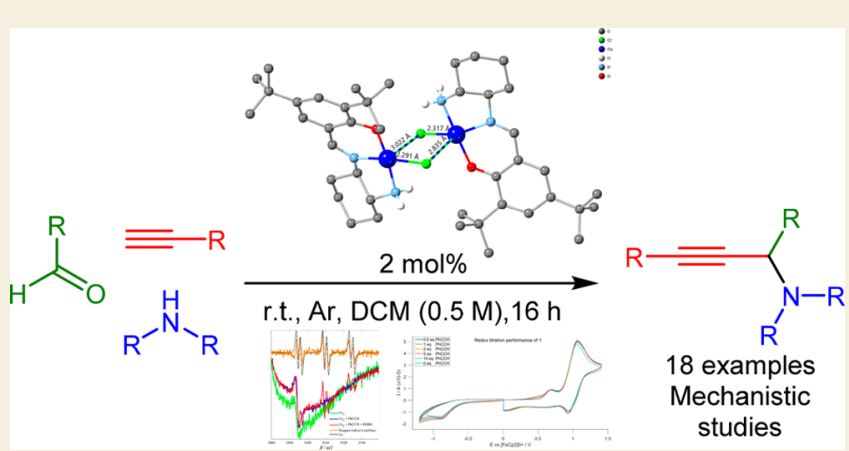
radical initiates an alkyne $\mathrm{C}-\mathrm{H}$ bond activation process via a fourmembered ring $\left(\mathrm{Cu}(\mathrm{II})-\mathrm{O} \cdots \mathrm{H}-\mathrm{C}_{\text {alkyne }}\right)$ intermediate. This unusual $\mathrm{C}-\mathrm{H}$ activation method is applicable for the efficient synthesis of propargylamines, without additives, within $16 \mathrm{~h}$, at low loadings and in noncoordinating solvents including late-stage functionalization of important bioactive molecules. Single-crystal X-ray diffraction studies, postcatalysis, confirmed the framework's stability and showed that the metal center preserves its oxidation state. The scope and limitations of this unconventional protocol are discussed.

KEYWORDS: copper, ligand design, $C-H$ activation, catalysis, radical, DFT, EPR, propargylamines

\section{INTRODUCTION}

Copper catalysis is frequently used for molecular transformations of natural products, bioactive molecules, agrochemicals, and organic functional materials. ${ }^{1-5}$ Coupling reactions involving terminal alkynes in the construction of new $\mathrm{C}_{\mathrm{sp}}-\mathrm{X}$ bonds (where $\mathrm{X}=\mathrm{C}, \mathrm{O}$, or $\left.\mathrm{N}\right)^{3}$ are vital in the design of important organic scaffolds. Several studies have investigated the mechanism of these transformations initiated by well-characterized or in situ generated catalytic species. These studies aimed to optimize catalyst performance either by fine-tuning the coordination environment of the catalyst or by varying coligands, solvents, and temperature. Copper is redoxplural (0/I/II/III), so the oxidation state in the starting component may differ from those in the reaction intermediates. ${ }^{6,7}$ However, particular attention has been given to $\mathrm{Cu}(\mathrm{I})$ derivatives due to the well-documented use of $\mathrm{Cu}(\mathrm{I})$ alkyne and alkynide complexes in substrate activation. ${ }^{8-10}$ Mixedvalent paradigms of well-characterized or in situ generated polynuclear catalytic species are known. For example, a mixedvalent $\mathrm{Cu}(\mathrm{I} / \mathrm{II})$ complex was crystallographically characterized from a Glaser coupling, ${ }^{11}$ and dicopper $\mathrm{Cu}(\mathrm{I} / \mathrm{I})$ and $\mathrm{Cu}(\mathrm{I} / \mathrm{II})$ complexes were used in click chemistry. ${ }^{12}$ Furthermore, monitoring of in situ generated species suggests a $\mathrm{Cu}$ (II)/ $\mathrm{Cu}(\mathrm{I})$ synergistic cooperation for alkyne $\mathrm{C}-\mathrm{H}$ activation $^{13}$ or direct observation of reduction of $\mathrm{Cu}$ (II) to $\mathrm{Cu}(\mathrm{I})$ by terminal alkynes. ${ }^{14}$ The general notion in organocopper chemistry is that the $\mathrm{Cu}(\mathrm{II})$-carbon $\sigma$-bond is unstable and subject to spontaneous decomposition; however, it may be a key step in organic transformations. ${ }^{4,5,15}$ These ideas suggest that more examples are needed to fully understand the role of $\mathrm{Cu}$ (II) species in terminal alkyne activation processes. This is a challenging task since $\mathrm{Cu}(\mathrm{II})$-aryl complexes are rare. Only recently, $\mathrm{Cu}$ (II) aryl complexes were found to promote $\mathrm{C}-\mathrm{C}^{16}$ and $\mathrm{C}-\mathrm{O}^{17}$ bond formation or have been proposed as vital intermediates in catalytic cycles. ${ }^{18,19}$

The successful design of catalytically efficient $\mathrm{Cu}(\mathrm{I})$ and $\mathrm{Cu}$ (II) complexes requires the design of specifically tailored ligands to cater for each oxidation state. For a $\mathrm{Cu}(\mathrm{I})$ species, bi- or tridentate ligands are chosen and for $\mathrm{Cu}$ (II) complexes ligands with higher denticity are used. Consequently, a broader library of ligands can be used in the latter case, and targeted

Received: July 12, 2021 
screening protocols can result in useful conclusions and optimized experimental conditions. Moreover, catalytic protocols involving well-characterized catalysts benefit from low loadings, reaction monitoring, and absence of additives. We have developed two different families of well-characterized $\mathrm{Cu}$ (II) components for alkyne $\mathrm{C}-\mathrm{H}$ activation in the absence of additives, ${ }^{20-24}$ using a variety of polydentate ligands. The first series incorporated mono- or bidentate electron-deficient ligands. ${ }^{20-22,24}$ In this case, activation required elevated temperatures, but for the bidentate examples, activation at room temperature under $\mathrm{N}_{2}$ was observed. This unusual performance was rationalized by a structural rearrangement of the complex and in situ reduction of $\mathrm{Cu}(\mathrm{II})$ to $\mathrm{Cu}(\mathrm{I})$, possibly triggered by the alkyne. ${ }^{14,24}$ For the second series, inspired by pioneering research on galactose oxidase and the use of $\mathrm{Cu}$ (II)-radical based complexes, ${ }^{25-27}$ we showed that a reusable $\mathrm{Cu}(\mathrm{II})$ complex, built from a tetradentate $\mathrm{N}_{2} \mathrm{O}_{2}$ salen-based ligand, promoted alkyne $\mathrm{C}-\mathrm{H}$ activation at room temperature, within $72 \mathrm{~h}$, or $0.5 \mathrm{~h}$ at elevated temperature. ${ }^{23}$ Mechanistic and theoretical studies suggested a radical-based and single-electron transfer (SET) mechanism. Based on this evidence, we hypothesized that fine-tuning of the salen ligand and its respective $\mathrm{Cu}$ (II) complex would be key for an optimized $\mathrm{C}-\mathrm{H}$ activation protocol. Inspired by recent results on an indium complex, built from a tridentate ligand, that was shown to facilitate a copolymerization reaction ${ }^{28}$ and the excellent performance of a similar tridentate ligand in an asymmetric Grignard synthesis of tertiary alcohols, ${ }^{29}$ we reasoned that the use of the tridentate monoprotic ligand $\mathrm{HL}\left(\mathrm{N}_{2} \mathrm{O}\right)$ (Scheme 1) would provide a $\mathrm{Cu}(\mathrm{II})$ complex

\section{Scheme 1. Well-Characterized Salen-Based Examples for Efficient A3 Coupling}
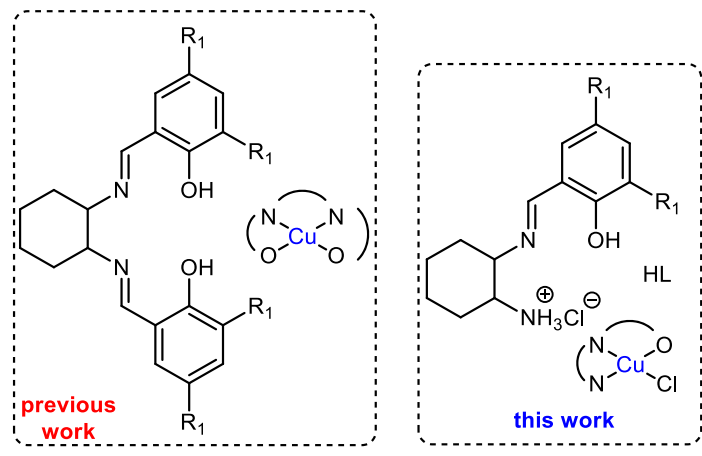

efficient for alkyne activation at room temperature. The ability to generate a phenoxide ion in the ligand would facilitate radical formation while a neutral amino group could temporarily accommodate the abstracted acetylenic proton. $^{23,30}$ The reaction of $\mathrm{HL}$ with a $\mathrm{Cu}(\mathrm{II}) \mathrm{X}_{2}$ salt could yield the $[\mathrm{Cu}(\mathrm{II}) \mathrm{LX}]$ and/or $\left[\mathrm{CuL}_{2}\right]$ species, and the latter would be likely to be catalytically inactive. Therefore, selecting the appropriate metal salt and metal/ligand ratio are crucial parameters in the design of the catalyst. In this work, we report the synthesis and characterization of a new $\mathrm{Cu}$ (II) complex $\left[\mathrm{Cu}(\mathrm{II})_{2} \mathrm{~L}_{2}\left(\mu_{2}-\mathrm{Cl}\right) \mathrm{Cl}\right](\mathbf{1})$ and its ability to activate alkynes at room temperature. Cyclic voltammetry, EPR, single-crystal Xray diffraction (SXRD), and theoretical studies corroborate a radical alkyne activation process via a four-membered ring $\left(\mathrm{Cu}-\mathrm{O} \cdots \mathrm{H}-\mathrm{C}_{\text {alkyne }}\right)$.

\section{RESULTS AND DISCUSSION}

trans-2-Aminocyclohexyl(imino)methyl)-4,6-di-tert-butylphenol hydrochloride, $\mathbf{H L} \cdot \mathbf{H C l}$, was synthesized in two steps from the commercially available racemic trans- $N$-boc-1,2-cyclohexanediamine (Scheme 2). First, condensation with 3,5-di-

Scheme 2. Synthesis of Dimeric Copper Catalyst $\left[\mathrm{Cu}(\mathrm{II})_{2} \mathrm{~L}_{2}\left(\mu_{2}-\mathrm{Cl}\right) \mathrm{Cl}\right](1)$

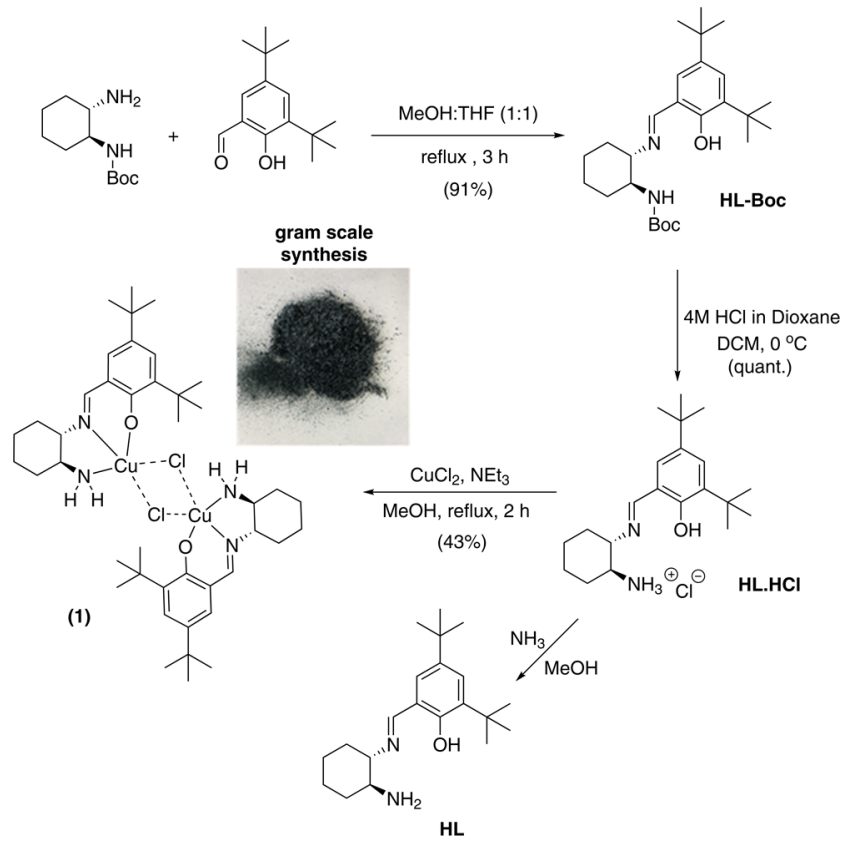

tert-butylsalicylaldehyde affords the Boc-protected Schiff base, HL-Boc, which is then deprotected with $\mathrm{HCl}$ to afford $\mathrm{HL}$ as its $\mathrm{HCl}$ salt in quantitative yield. Due to the susceptibility of the $\mathbf{H L} \cdot \mathbf{H C l}$ ligand to hydrolyze to the corresponding amine and aldehyde as observed by ${ }^{1} \mathrm{H}$ NMR, it was employed directly in the synthesis of the copper catalyst, 1, without further purification. Attempts to synthesize the desired copper complex from the free base of HL failed due to the insolubility of the latter in suitable protic solvents. Given the monoprotic character of the ligand, we chose the weakly binding chloride anion to prevent the formation of the $\mathrm{CuL}_{2}$ species. The openair reaction of $\mathbf{H L} \cdot \mathbf{H C l}, \mathrm{CuCl}_{2}$, and $\mathrm{Et}_{3} \mathrm{~N}$, in $\mathrm{MeOH}$, in a molar ratio 1:1:3, afforded compound 1 in $43 \%$ yield. The air-stable green crystalline material can be synthesized on a gram scale (Figure S6) and was characterized by SXRD (Figure 1), IR, UV-vis, electron paramagnetic resonance (EPR) spectroscopy, and cyclic voltammetry (CV) (see Figures S7-S14).

Compound $\mathbf{1}$, in the solid-state, consists of an asymmetric dimer (Figure 1). The $\mathrm{Cu}(\mathrm{II})$ coordination shows two different elongated $\mathrm{Cu}-\mathrm{Cl}$ bonds. The $\mathrm{Cu}(1)-\mathrm{Cl}(2)$ bond length is $2.8345(10) \AA$, whereas the $\mathrm{Cu}(2)-\mathrm{Cl}(1)$ bond length $[3.0217(9) \AA]$ is significantly longer. However, based on a literature survey ${ }^{31-34}$ and experimental data (see EPR discussion), we consider $\mathrm{Cl}(2)$ and $\mathrm{Cl}(1)$ as bridging and terminal chlorides, respectively. Geometrical calculations (see Table S1) show that the coordination geometry of $\mathrm{Cu}(1)$ is a hybrid of a square pyramidal or vacant octahedron $\left(\mathrm{N}_{2} \mathrm{OCl}_{2}\right)$, while that of $\mathrm{Cu}(2)$ is square planar $\left(\mathrm{N}_{2} \mathrm{OCl}\right)$. The $\mathrm{Cu}-\mathrm{O}$, $\mathrm{Cu}-\mathrm{N}$, and $\mathrm{Cu}-\mathrm{Cl}$ bond distances (Table $\mathrm{S} 2$ ) are typical for a $\mathrm{Cu}$ (II) compound, while bond valence calculations analysis (Table S3) suggests that both $\mathrm{Cu}$ centers are in oxidation state 


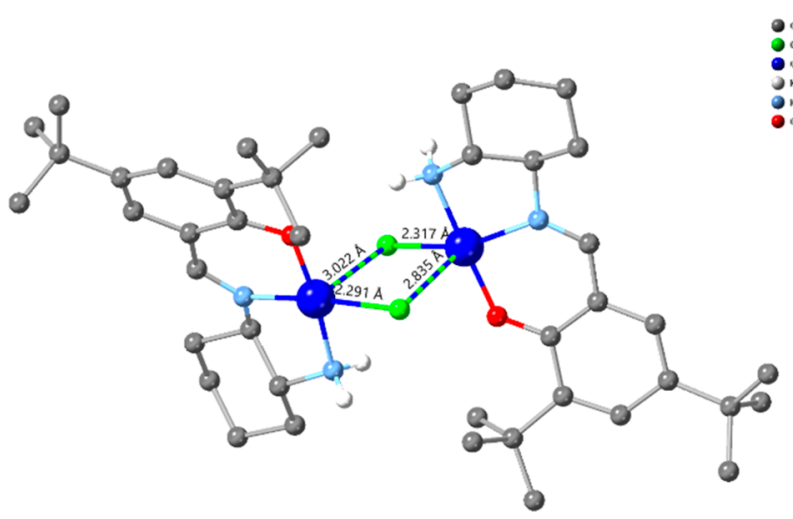

Figure 1. Crystal structure of $\mathbf{1}$. All $\mathrm{H}$ atoms except $\mathrm{NH}_{2}$ are omitted for clarity. The elongated $\mathrm{Cu}-\mathrm{Cl}$ bonds are shown with dashed lines.

2. The $\mathrm{C}-\mathrm{C}$ and $\mathrm{C}=\mathrm{N}$ and $\mathrm{C}-\mathrm{O}$ bonds are typical for a salen-based ligand. ${ }^{35-50}$ The bridging chloride ion brings the two $\mathrm{Cu}(\mathrm{II})$ centers together with $\mathrm{Cu} \cdots \mathrm{Cu} 3.6639(6) \AA$, and the salen ligands complete the two coordination spheres.

Elemental ( $\mathrm{CHN})$ and thermogravimetric analysis (TG) confirmed macroscopic purity and thermal stability up to 202 ${ }^{\circ} \mathrm{C}$ respectively. Electron spray ionization mass spectrometry (ESI-MS) of 1 showed two peaks in the time-of-flight (TOFMS-ES) positive-ion mode at $m / z=831.3768$ and 392.1826, which, respectively, correspond to the dimeric disodium species $\left[\mathrm{Cu}_{2} \mathrm{~L}_{2}\right] \mathrm{Na}_{2}$ and monomeric $[\mathrm{CuL}]$ species (Figure $\mathrm{S} 8$ ). The $\mathrm{UV}$-vis spectrum in $\mathrm{CH}_{2} \mathrm{Cl}_{2}$ is typical for a $\mathrm{CuN}_{2} \mathrm{OCl}$ chromophore (Figure S10). To further understand the solution behavior of 1 , we performed $\mathrm{CV}$ studies in $\mathrm{CH}_{2} \mathrm{Cl}_{2}$ under a $\mathrm{N}_{2}$ atmosphere and with different current rates. The cyclic voltammograms of $\mathbf{1}$ display two wellseparated one-electron reversible redox waves at $E_{1 / 2}^{1}=0.30 \mathrm{~V}$ and $E_{1 / 2}^{2}=0.71 \mathrm{~V}$ vs $\mathrm{Fc}^{+} / \mathrm{Fc}$ (Figure 2 upper); ${ }^{35,46,51-55}$ however, in the reductive region, a nonreversible process is feasible.
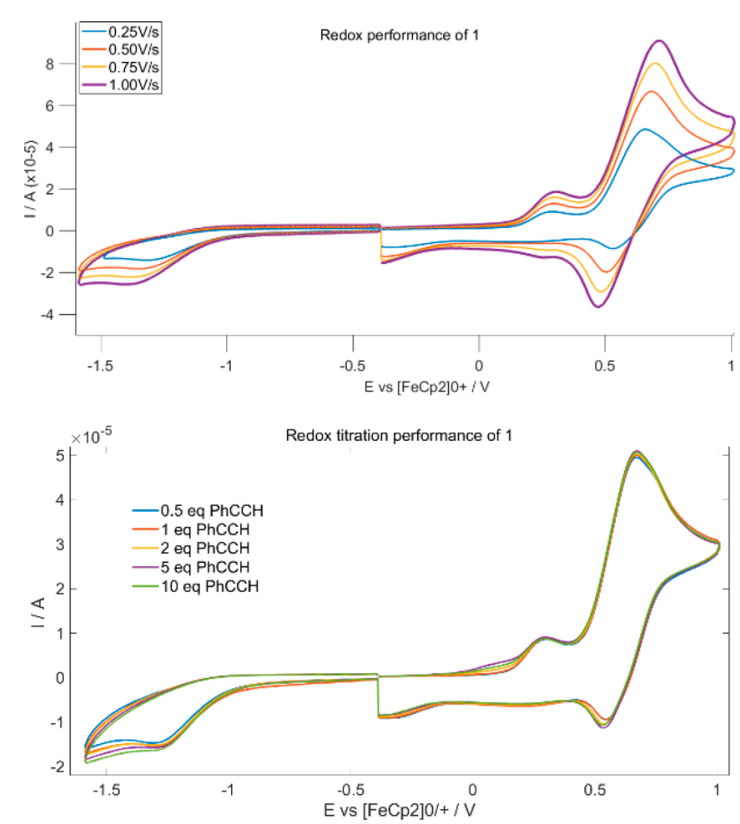

Figure 2. CV of compound $\mathbf{1}$ (upper) in the presence of phenylacetylene (lower).
Based on literature evidence, ${ }^{35,48,56,57}$ the oxidation process shows a typical behavior for this kind of $\mathrm{Cu}$ (II) complexes compounds. It may correspond to either oxidation of a $\pi$ radical that would lead to the formation of an iminobenzoquinone from the iminobenzosemiquinone unit or oxidation of the $\mathrm{Cu}(\mathrm{II})$-coordinated phenolate unit that would generate a $\mathrm{Cu}$ (II)-phenoxyl radical. ${ }^{51}$ Cyclic voltammetry studies of $\mathbf{H L}$ show that the ligand exhibits no reductive process (Figure S11). To confirm this hypothesis and before continuing to catalytic studies, we studied the compound in solution by EPR (Figures $\mathrm{S} 13$ and S14). Spectra from frozen $\mathrm{CH}_{2} \mathrm{Cl}_{2}$ solutions $\left(0.77 \mathrm{mM}\right.$ for $\left[\mathrm{Cu}_{2}\right]$ ), collected at $100 \mathrm{~K}$, revealed a principal component of axial, hyperfine-split spectra, characteristic of mononuclear $\mathrm{Cu}(\mathrm{II})$ complexes. Superposed on these were hyperfine-split, half-field transitions, indicating interacting species in solution. An additional feature at $g=1.85$ supports this notion. Given the low concentration of the solution, these could stem from intramolecular interactions within dinuclear species, rather than intermolecular interactions between mononuclear species. This suggests that a fraction of the complex retains its dinuclear structure upon dissolution. The spectra were simulated considering a mixture of mononuclear (85\%) and dinuclear (15\%) species. For the dinuclear species, given the crystal structure, which reveals a superexchange pathway through the $\mathrm{Cu}$ (II) ions' nonmagnetic orbitals, only dipolar interactions were considered $(J=0)$. For these, the relative orientations of the two $g$-tensors were explicitly taken into consideration, assuming two identical ions, whose $g$ tensors were collinear with their $A$-tensors. Assuming $\mathrm{Cu}(1)$ as a frame of reference with the $z$-axis coinciding with the $\mathrm{d}_{z 2}$ orbital orientation, then the free variables were the angle of the $\mathrm{Cu}(2)$ concerning the $z$-axis, the intermolecular distance $r$. Attempts were made to simulate a tilt of the $g_{2}$-tensor with respect to its local $y$-axis, but these did not afford significant improvements to the fits ${ }^{58}$ (Figures S12 and S13).

Propargylamines ${ }^{59,60}$ are essential precursors in the synthesis of high value products, including isoindolines, ${ }^{61}$ oxazolidines, ${ }^{62}$ pyridones, $^{63,64}$ and alkaloids. ${ }^{63-67}$ Following our work on $\mathrm{Cu}$ (II) protocols in $\mathrm{A}^{3}$ couplings, ${ }^{23,24}$ we selected cyclohexanecarboxaldehyde, pyrrolidine, and phenylacetylene as model substrates. Each catalytic reaction was performed in duplicate, and reproducibility and yields are given as an average with deviations of $<10 \%$. Screenings of concentration, time, and solvent are given in the Supporting Information (Table S5). Conversion to the desired product was complete within $16 \mathrm{~h}$ at room temperature under an $\mathrm{Ar}$ atmosphere and a significant improvement over our previous work (72 h). The present protocol is, to the best of our knowledge, ${ }^{68,69}$ an example of a $\mathrm{Cu}$ (II) $\mathrm{A}^{3}$-coupling catalyst that is efficient at room temperature over a relatively short time. The scope of the reaction is shown in Figure 3, applicable to aliphatic aldehydes/secondary amines and alkynes. Yields of the resulting propargylic amines were good to excellent. The reactions with aryl aldehydes or aliphatic amines at room temperature are unsuccessful; however, by increasing the temperature of the reaction (reflux) the corresponding products are obtained in good to moderate yields, but on this occasion a different catalytic pathway may be followed. Therefore, we decided not to include these data in the current article.

Purification was achieved using normal-phase chromatography with hexane and ethyl acetate as eluents with the compounds characterized by ${ }^{1} \mathrm{H}$ and ${ }^{13} \mathrm{C}$ NMR spectroscopy 

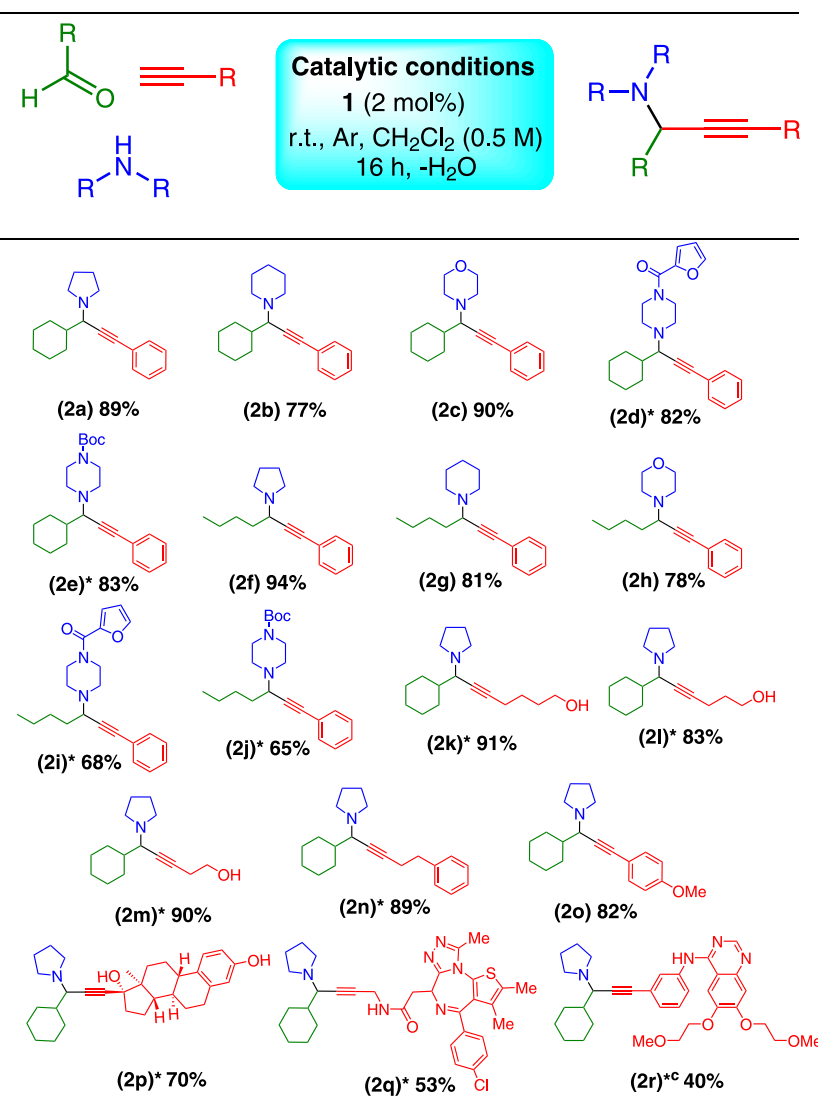

Figure 3. Substrate scope of the reaction with aldehydes, secondary amines, and alkynes. ${ }^{\mathrm{a}, \mathrm{b}}$ (a) Isolated yield, after purification. (b) Reaction conditions; catalyst ( $2 \mathrm{~mol} \%), 1.0 \mathrm{mmol}$ aldehyde, 1.1 mmol amine, $1.2 \mathrm{mmol}$ alkyne, molecular sieves $4 \AA$, $16 \mathrm{~h}, \mathrm{Ar}$ atmosphere, room temperature, solvent dichloromethane, concentration $0.5 \mathrm{M}$. (c) An extra 1 equiv of pyrrolidine was used to desalt the starting material.

and HRMS. This method was used in the isolation of eleven previously unknown compounds (* in Figure 3 ), demonstrating the potential of this catalytic protocol in the synthesis of new organic compounds.

Ethinylestradiol is widely used as an estrogen-based oral contraceptive. ${ }^{70}$ Copper-catalyzed alkyne azide cycloaddition reactions have been used to develop triazole derivatives of ethinylestradiol. Related derivatives have cytotoxic activity against human cancer cell lines and can act as positron emission tomography (PET) imaging agents for estrogen receptor positive $\left(\mathrm{ER}^{+}\right)$breast cancer. ${ }^{71,72}$ To demonstrate the powerful scope of our catalyst in an $\mathrm{A}^{3}$ reaction, 1 was employed in the synthesis of a propargylamine steroid derivative, $2 \mathbf{p}$, which was isolated in good yield as a white solid. Other pharmaceutically relevant examples include $\mathrm{A}^{3}$ reactions on a (BRD4) bromodomain inhibitor JQ1 analogue, $^{73}$ to afford $\mathbf{2 q}$, and on the clinically used epidermal growth factor receptor kinase inhibitor erlotinib, to afford $\mathbf{2 r}$. Therefore, we have shown that this chemistry can have impactful, late-stage applications relevant to the pharmaceutical industry, particularly as $\mathrm{A}^{3}$-couplings can introduce new $\mathrm{sp}^{3}$ chiral centers, with escape from flatland applications that are often employed to improve the physiochemical properties of compounds. ${ }^{74}$ Moreover, these reactions occur in the presence of other competing nucleophilic groups including alcohol, phenol, aniline, and amides.

\section{MECHANISTIC UNDERSTANDING}

We designed in situ CV, IR, and EPR studies in a sense to mimic the catalytic reaction; the catalyst/alkyne ratio is $2: 100$. Our attempts to record the corresponding UV-vis or NMR data of highly concentrated and paramagnetic samples failed to provide conclusive results. Titration CV studies on 1, under an $\mathrm{N}_{2}$ atmosphere, with $\mathrm{PhC} \equiv \mathrm{C}-\mathrm{H}(0.5,1,2,5$, and 10 equiv) showed no significant effects on the oxidative process (Figure 2 lower) and only a slightly modified cathodic behavior, which suggests that during the $\mathrm{PhC} \equiv \mathrm{C}-\mathrm{H}$ addition complex $\mathbf{1}$ is stable. The metal center retains its oxidation state; thus, this one electron reduction process may correspond to reduction of the $\{1-\mathrm{PhCCH})$ complex. Following previous experiments, ${ }^{23}$ we monitored these titrations by EPR (Figure 4). Frozen and

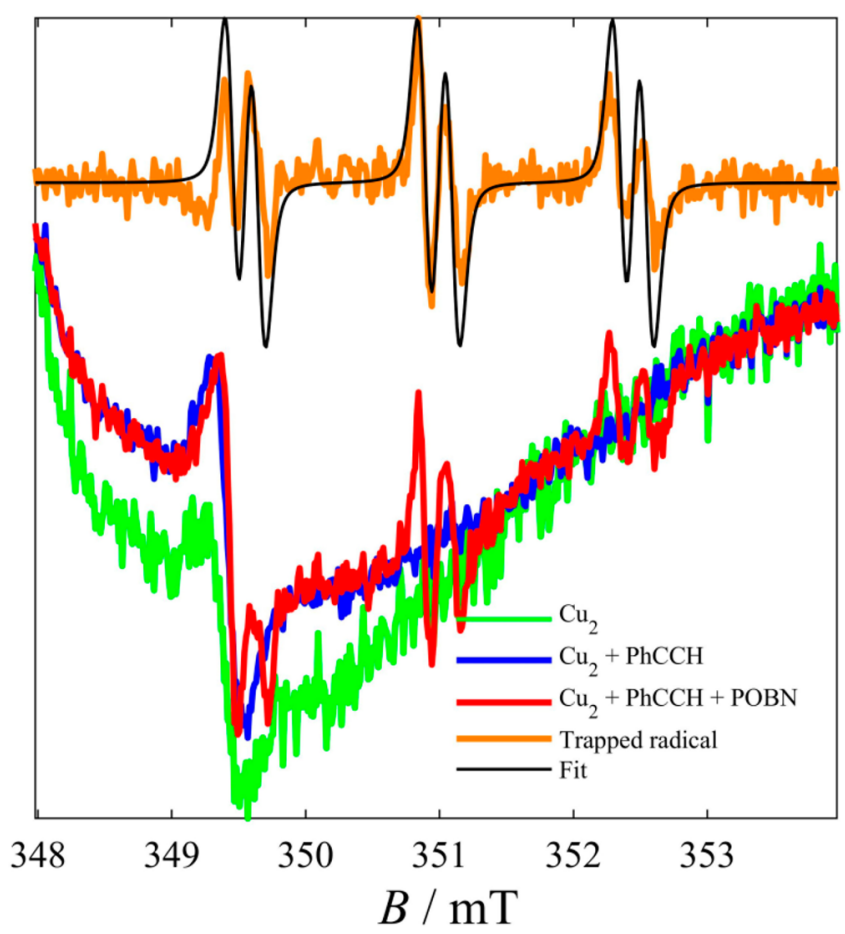

Figure 4. EPR spectra of fluid $\mathrm{CH}_{2} \mathrm{Cl}_{2}$ solutions $(300 \mathrm{~K}$ ) of $\mathbf{1}$ (green line), $1+\mathrm{Ph}-\mathrm{C} \equiv \mathrm{C}-\mathrm{H}(10 \%)$ (blue line), and $1+\mathrm{Ph}-\mathrm{C} \equiv \mathrm{C}-\mathrm{H}$ $(10 \%)+$ POBN $(10 \%)$ (red line). The trapped radical (orange line) is the difference between the red and blue spectra. Experimental conditions: $C=0.50 \mathrm{mM}, T=300 \mathrm{~K}, f_{\mathrm{MW}}=9.855 \mathrm{GHz} ; P_{\mathrm{MW}}=4.53$ $\mathrm{mW}, B_{\mathrm{mod}}=0.5 \mathrm{G}_{\mathrm{pp}}$.

fluid solution EPR studies on pure 1 gave a hyperfine-split axial signal typical of a mononuclear $\mathrm{Cu}^{\mathrm{II}}$ complex in a Jahn-Teller elongated ligand field. In addition, they revealed a minor component of hyperfine-split half-field transitions and a $g=$ 1.85 absorption. The latter component was analyzed as derived from a dipole-coupled species of $\mathrm{Cu}^{\mathrm{II}}$ ions (see the SI for fitting details). These results demonstrated that $\sim 85 \%$ of the complex decomposes into mononuclear species in solution, while a smaller fraction of dinuclear 1 persists. We performed $\mathrm{PhC} \equiv$ $\mathrm{C}-\mathrm{H}$ loading experiments in the absence and presence of a spin trap $\alpha$-(4-pyridyl $N$-oxide)- $N$-tert-butylnitrone (POBN). These show that alkyne loading further promotes the dimer's dissociation into monomers. We conclude that complex $\mathbf{1}$, 
A

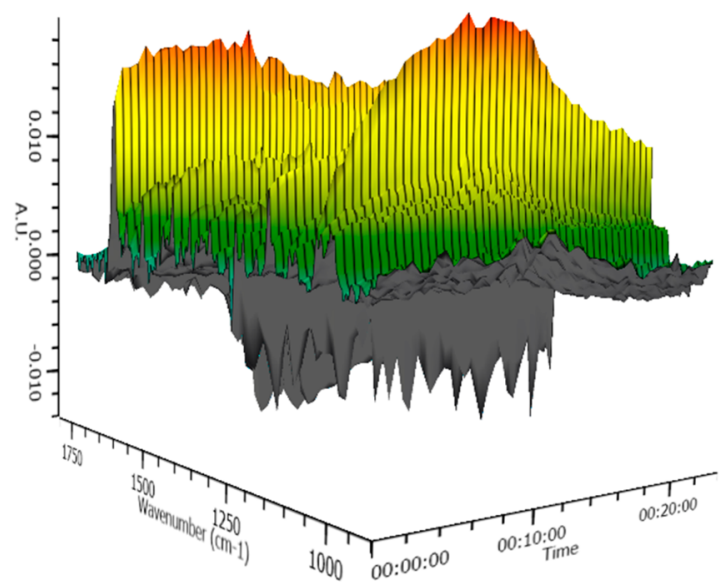

C

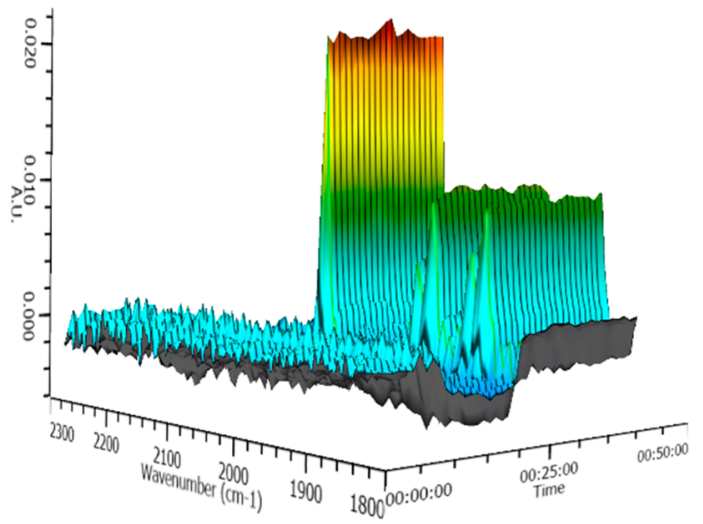

B

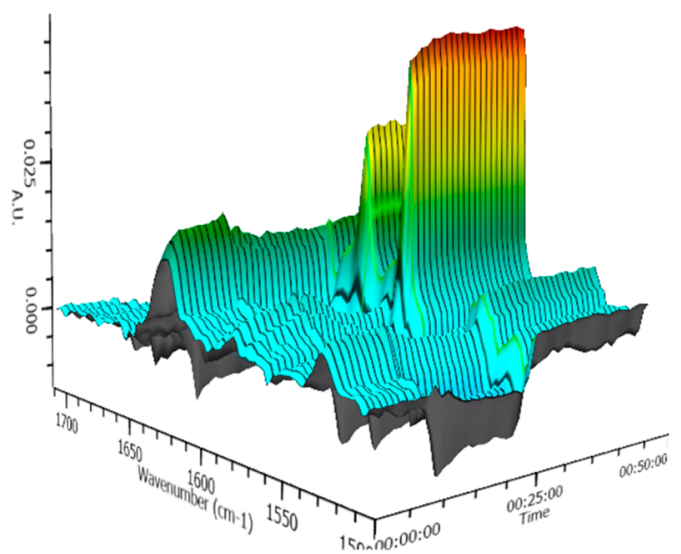

D

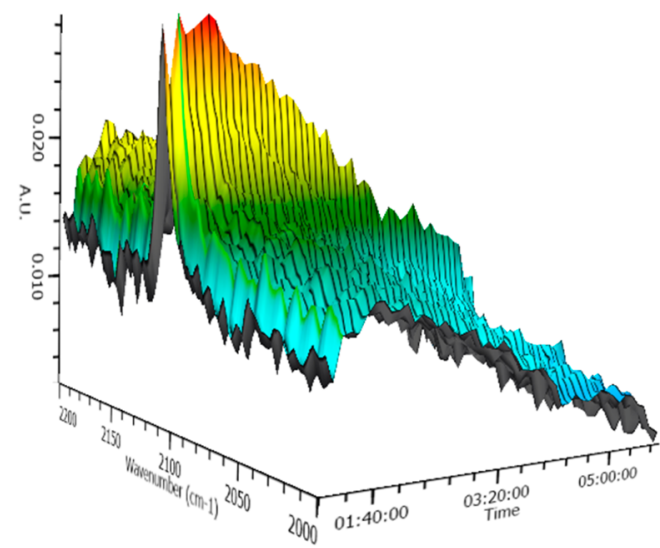

Figure 5. In situ IR studies of $\mathbf{1}$ (A), 1 and phenylacetylene (1:50 ratio) (B,C), and $\mathbf{1}$ and cyclohexanecarboxaldehyde, pyrrolidine, and phenylacetylene (1:50:50:50) (D).

upon dissolution, exists in an equilibrium of $85 \%$ (monomer)$15 \%$ (dimer); however, the alkyne loading drives the equilibrium to $100 \%$ (monomer) - $0 \%$ (dimer). In the absence of the spin trap, no additional signals were detected. In the presence of POBN, a characteristic signal was recorded which, after subtraction of the $\mathrm{Cu}$ (II) complex spectrum, was nicely fitted to a radical system coupled to a nitrogen and proton nuclei, with parameters $g=2.006, A_{\mathrm{N}}=41.2 \mathrm{MHz}(14.71 \mathrm{G})$, $A_{1 \mathrm{H}}=5.96 \mathrm{MHz}(2.13 \mathrm{G})$. These values are characteristic of POBN-radical species (Scheme S2). ${ }^{75}$ The typical values of this trapped radical do not allow further characterization, although, based on the prior art, formation of a $\mathrm{Cu}$ (II)phenoxyl radical species seems likely. ${ }^{54,76}$ However, the key conclusion of this experiment is that the $\mathrm{Cu}$ center retains its oxidation state during this process.

To further understand the solution behavior of 1 , we performed time-dependent in situ IR studies at room temperature, under $\mathrm{N}_{2}$ atmosphere and $\mathrm{CH}_{2} \mathrm{Cl}_{2}$ solvent (Figure 5A). Monitoring of the dark green solution for 20 min identifies a structural change. The intensity of the peaks at 1627 and $1055 \mathrm{~cm}^{-1}$ indicative for the $\mathrm{C}=\mathrm{N}$ and $\mathrm{C}-\mathrm{O}$ bonds, respectively, fluctuates. This differentiation possibly can be attributed to the above-mentioned dimeric-monomeric equilibrium. Then, upon phenyacetylene addition in catalytic loading (1:50 ratio), the intensity of the peak at $1627 \mathrm{~cm}^{-1}$ decreases over time (Figure 5B) and possibly indicates the population of the monomeric species $\left(\mathbf{1}^{\prime}\right)$, as noted in the EPR studies. At the same time, the intensity of the peak at 2112 $\mathrm{cm}^{-1}$, indicative of the $\mathrm{C} \equiv \mathrm{C}$ stretching bond, decreases over time (Figure $5 \mathrm{C}$ ), indicating interaction of the phenylacetylene moiety with $\mathbf{1}^{\prime}$. Finally, after the addition of the remaining substrates (cyclohexanecarboxaldehyde and pyrrolidine, Figure $5 \mathrm{D})$, the intensity of the $\mathrm{C} \equiv \mathrm{C}$ stretching bond peak declines over time, thus supporting the room temperature $\mathrm{C}-\mathrm{H}$ activation process.

Given that the catalytic and CV studies were performed at room temperature and the EPR and SXRD studies were performed at $100 \mathrm{~K}$, we considered that a variable-temperature SXRD study would shed light on structural features and behavior of compound 1. SXRD data of compound 1 at three temperatures $200 \mathrm{~K}\left(\mathbf{1}^{\mathbf{2 0 0}}\right), 298 \mathrm{~K}\left(\mathbf{1}^{298}\right)$, and $330 \mathrm{~K}\left(\mathbf{1}^{330}\right)$ showed only slight changes in the bond distances and angles (Tables $\mathrm{S} 1$ and S2, Figure $\mathrm{S} 14$ ) round the $\mathrm{Cu}$ centers. It is evident that compound $\mathbf{1}$, at $330 \mathrm{~K}$, exists as a monomer in the solid state, whereas the bond distances and angles of the organic platform, in all temperatures, are unaffected. The SXRD data at $298 \mathrm{~K}$, at which the catalytic conversion takes place, indicate elongation of the $\mathrm{Cu}(1)-\mathrm{Cl}(2)$ bond to 2.9562(14), (the $\mathrm{Cu}(2)-\mathrm{Cl}(1)$ bond is 3.0806(14)), suggesting very weak interaction to form a dimeric species. From these studies, it is evident that in the solution phases at $298 \mathrm{~K}$, compound $\mathbf{1}$ predominantly exists as a monomer $\left(\mathbf{1}^{\prime}\right)$.

We performed control synthetic experiments to establish a reasonable mechanistic pathway. The open-air reaction (entry 
2 , Table 1) yielded $2 \mathbf{a}$ in a moderate yield suggesting the need for an inert atmosphere. The different yields (entries 1 and 2,

Table 1. Various Experiments to Elucidate the Mechanism

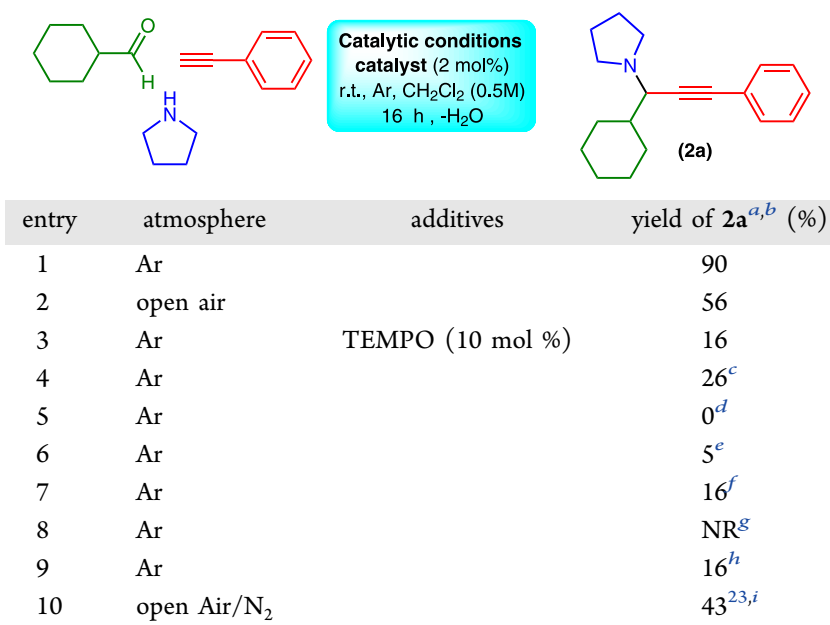

${ }^{a}$ Isolated yields. ${ }^{b}$ Reaction conditions, catalyst ( $\left.2 \mathrm{~mol} \%\right), 1.0 \mathrm{mmol}$ of aldehyde, $1.1 \mathrm{mmol}$ of amine, $1.2 \mathrm{mmol}$ of alkyne, molecular sieves $4 \AA$, solvent; dichloromethane $2 \mathrm{~mL}$, concentration $0.5 \mathrm{M}$, room temperature, Ar atmosphere, $16 \mathrm{~h}$. ${ }^{c}$ In situ formation of the catalyst $\mathrm{HL} / \mathrm{CuCl}_{2} .{ }^{d}$ Reaction with HL $(2 \mathrm{~mol} \%) .{ }^{e}$ Reaction with $\mathrm{CuCl}_{2}(2$

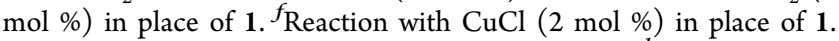

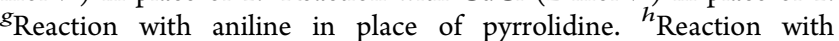
recovered material 3 (2 mol \%) (vide supra), conversion by ${ }^{1} \mathrm{H}$ NMR. ${ }^{i}$ Reaction completed in $24 \mathrm{~h}$.

Table 1) may be due to catalyst structural changes, or a different mechanistic pathway. Both hypotheses could be rationalized if we take into account that similar complexes in the open air can be used as one-electron oxidized models of galactose oxidase $\mathrm{e}^{25-27}$ and that the existence of $\mathrm{Cu}-\mathrm{O}_{2}-\mathrm{Cu}$ species, that may inhibit alkyne binding, cannot be excluded. ${ }^{77-80}$ The EPR experiments (see above) confirmed a radical presence; therefore, we studied the reaction in the presence of a radical trap TEMPO (10\%) under an Ar atmosphere (entry 3, Table 1), which led to $2 \mathrm{a}$ in $16 \%$ yield. The significant difference in yields can be rationalized by consideration of a 2 -fold TEMPO role, either to suppress the radical formation, as noted in our previous studies, ${ }^{23}$ or to oxidize the amine. ${ }^{81}$ The catalytic reaction with in situ blending of $\mathrm{HL}$ and $\mathrm{CuCl}_{2}$ gives $2 \mathrm{a}$ in $26 \%$ yield (entry 4 , Table 1 ). This result indicates that other noncatalytic $\mathrm{Cu}_{x} \mathrm{~L}_{y} \mathrm{Cl}_{z}$ species may form, thus establishing the need for a precisely characterized species. However, to examine the ligand's contribution to the catalytic activity, we experimented with HL ( 2 mol \%) alone, without $\mathrm{Cu}$ (entry 5, Table 1), and observed no product formation. We then examined the efficacy of copper salts in different oxidation states (entries 6 and 7, Table 1) in $2 \%$ loadings, which yielded $2 \mathrm{a}$ in $5 \%$ (using $\mathrm{CuCl}_{2}$ ) and $16 \%$ (using $\mathrm{CuCl}$ ). In these experiments, the catalytic pathway may be a different, and the reduction of $\mathrm{Cu}$ (II) to $\mathrm{Cu}(\mathrm{I})$ by terminal alkynes is feasible. ${ }^{13,14} \mathrm{Next}$, we attempted to expand the scope of the reaction to primary amines; however, the reaction with aniline (entry 8 , Table 1 ) failed to yield the desired product.

Last, we attempted to recrystallize a green solid obtained from all the control experiments, post catalysis, with dichloromethane. From the reactions in open air (entry 2, Table 1), small green crystals were obtained, and their crystal structure was determined. The SXRD data at $120 \mathrm{~K}$ reveal the existence of a different dimeric complex formulated as $[\mathrm{Cu}$ (II) $\left.{ }_{2} \mathrm{~L}_{2}\left(\mathrm{C}_{6} \mathrm{H}_{10} \mathrm{CO}_{2}\right)_{2}\right]$ (3, Figure 6). Compound 3 is built

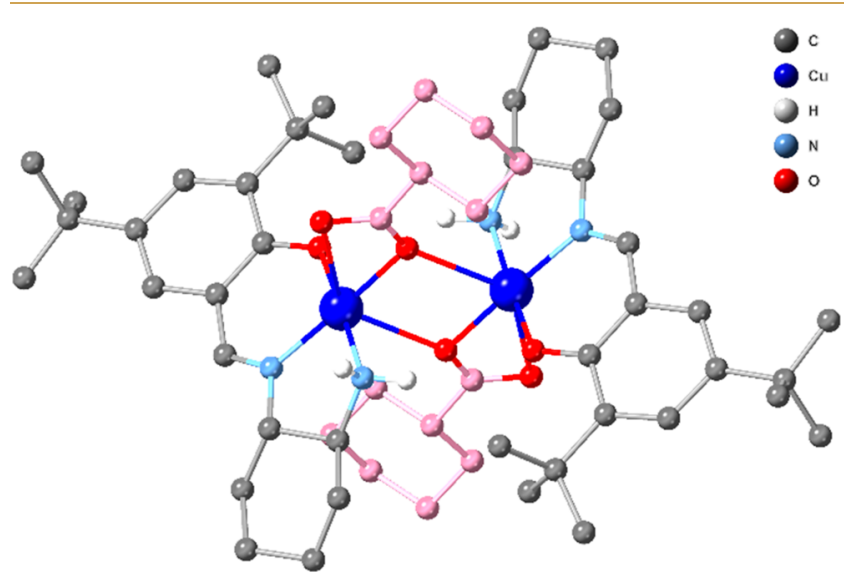

Figure 6. Crystal structure of the recovered material 3. All H-atoms except $\mathrm{NH}_{2}$ are omitted, and $\mathrm{C}$ atoms of carboxylate unit are drawn in light purple for clarity.

from the starting organic ligand and cyclohexanecarboxylate bridging anions. We assume the carboxylate formation is the result of the oxidation of unreacted cyclohexanecarboxaldehyde during the workup process. For the reactions performed under an $\mathrm{O}_{2}$ atmosphere, compound 3 is recovered almost quantitatively. Interestingly, the use of 3 in $2 \%$ loading as catalyst in the parent reaction yielded 2a in $16 \%$ (conversion), indicating that the presence of strongly binding anions inhibits the catalytic activity which may be the cause of lower yields observed in open air (entry 9, Table 1). Lastly, in none of the reactions was the redox $\mathrm{A}^{3}$-product observed in the crude ${ }^{1} \mathrm{H}$ NMR. $^{82}$

Taking all the above into account and considering the following observations, (i) the absence of side products (heterocoupling, bis-adduct) or metallic $\mathrm{Cu}$ precipitate in the crude NMRs, (ii) the EPR experiments, discounting the possibility of two monomers activating the $\mathrm{Ph}-\mathrm{C} \equiv \mathrm{C}-\mathrm{H}$ entity, or the existence of a dimeric species, (iii) that the coordinating metal labilizes the terminal hydrogen, allowing a weak base ( $\mathrm{Cl}^{-}$anion or $\mathrm{N} / \mathrm{O}$ heteroatoms of the ligand) to deprotonate the alkyne, thus forming the activated acetylide as has been confirmed by IR and NMR studies, ${ }^{83,84}$ (iv) the fact that the substituted phenolate and primary amines have similar $\mathrm{pK}_{\mathrm{b}}$ values, ${ }^{85-88}$ and (v) that the activated acetylide subsequently couples with the corresponding imine, ${ }^{89-91}$ we propose the following mechanism (Scheme 3). Compound 1 in solution exists as an $85-15 \%$ monomer-dimer equilibrium, and the excess of $\mathrm{Ph}-\mathrm{C} \equiv \mathrm{C}-\mathrm{H}$ populates $\mathbf{1}^{\prime}$ (step 1 ). Then the alkyne binds to the monomer (step 2) and initiates activation (step 3 ). This procedure follows a 4-membered ring formation, which subsequently triggers the radical formation to complete the activation process while the imine moiety replaces the $\mathrm{Cl}^{-}$anion (step 4). Then, the acetylide couples with the in situ generated iminium species, which is formed via $\mathrm{H}^{+}$-mediated elimination of water ${ }^{90}$ (step 5) to form the propargylamine product (step 6). The final step involves catalyst regeneration and product release (step 7). The proposed mechanism resembles the one proposed by Knochel et al. $^{89}$ however, the major difference is that in the present case $\mathrm{Cu}$ in the precatalyst is in oxidation state II. 
Scheme 3. Proposed Mechanism for the $\mathrm{Cu}(\mathrm{II})$-Promoted $\mathrm{A}^{3}$ Coupling ${ }^{a}$

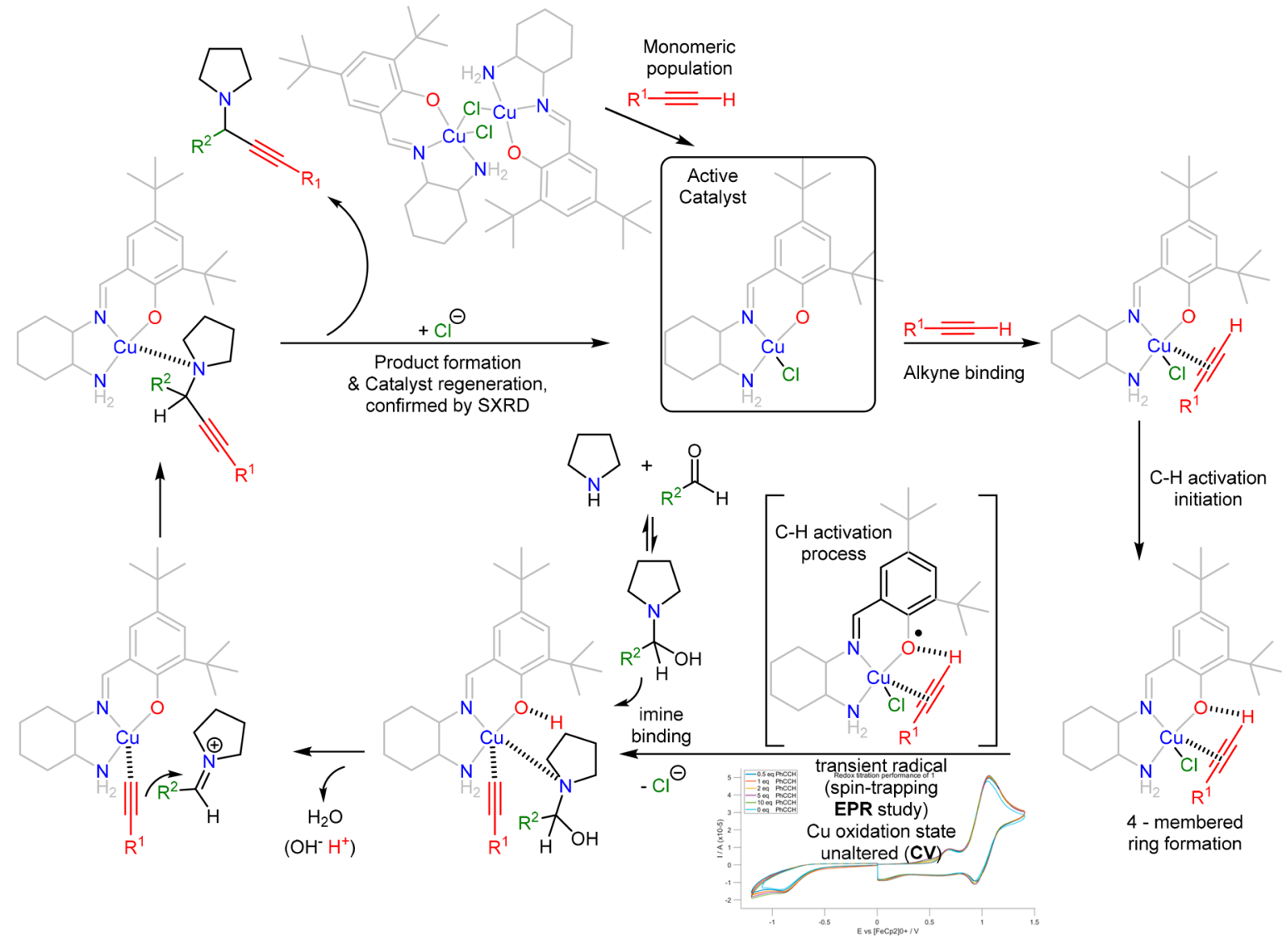

${ }^{a_{T}}$ The transient radical is formed during $\mathrm{C}-\mathrm{H}$ activation not the one directly observed by EPR; instead, we observe its spin-trapped adduct formed by reaction with POBN (Scheme S2).

\section{THEORETICAL CALCULATIONS}

Given the peculiar catalytic process observed, we further carried out theoretical calculations within Kohn-Sham density functional theory (DFT) at the OLYP/def2-SVP D3 level with PCM (dichloromethane) implicit solvation. Figure 7 showcases a qualitative reaction profile and a description of the electronic structure of key species. As mentioned earlier in the manuscript, initial activation of the alkyne by the monomeric neutral doublet 1 takes place by way of through-space interaction and surprisingly brings the resulting van der Waals (v-d-W) complex to about $5 \mathrm{kcal} / \mathrm{mol}$ more stable. We tentatively ascribe this to dispersion interactions and the relaxation toward quasi-tetrahedral symmetry of the copper center. Full activation through dative alkyne capture with concomitant leaving of neutral chlorine occurs, bringing the system to some $8 \mathrm{kcal} / \mathrm{mol}$ more energetic. Calculations highly suggest that the now nonhalogenated system needs to switch its state from doublet ${ }^{2} \mathrm{~A}$ to singlet ${ }^{1} \mathrm{~A}$. Combining this with the fact that (a) to be consistent in terms of full electronic energy, the departing chlorine has to be treated as nonsolvated species, (b) upon activation as mentioned in the previous step, the $\mathrm{Cl}-$ $\mathrm{Cu}$ bond distance increases, and (c) the number of electrons increases around the oxygen adjacent to the metal, we conclude that there is homolytic-like $\mathrm{Cu}-\mathrm{Cl}$ bond breaking, and subsequently, a nondirectional interaction between the $\mathrm{Cl}$ and the catalytic adduct takes place. To further support this, we optimized the activation structure with $\mathrm{Br}$ in lieu of $\mathrm{Cl}$; the $\mathrm{Cu}-\mathrm{N}$ bonds are not affected; however, the distance between the two radical centers, the $\mathrm{Cu}$ and the adjacent $\mathrm{O}$, is dependent on the nature of the halogen, with $\mathrm{Cu}-\mathrm{O}$ slightly longer in the chlorine species. Based on the analysis of charge displacement upon activation, it can be suggested that the alkyne induces electron movement toward the oxygen and the halogen centers with the concomitant electrophilic attack of the copper center on the alkyne, acquiring in the process a decrease in its oxidation state. In the next stage, akin to the first step, another through-space interaction brings the system to lower energy by $10 \mathrm{kcal} / \mathrm{mol}$, this time by $\mathrm{v}-\mathrm{d}-\mathrm{W}$ capture of $\mathrm{NR}_{2}$. One should note that conformational change occurs, contributing to the observed shift in energy. Full head-on interaction between the alkynyl carbon and the metal center follows with the liberated hydrogen scavenged by the oxygen, putting the system to $8 \mathrm{kcal} / \mathrm{mol}$ higher Fusion of the enamine and the alkyne with isochronous water production sets the system again to about $2 \mathrm{kcal} / \mathrm{mol}$ more stable. One can note that charge movement involves solely the alkyne carbons needed to form the $\mathrm{C}-\mathrm{C}$ bond. The additional role of the metal is evident at this stage, that is, to template the resulting $\mathrm{N}-\mathrm{C}-\mathrm{C}$ catenate. Lastly, a downward release of the product is associated with $10 \mathrm{kcal} / \mathrm{mol}$, with the accompanying reformation of the $\mathrm{Cu}-\mathrm{Cl}$ bond hence recycling the catalyst. Further interesting points need to be mentioned. First, the copper center switches from $\mathrm{Cu}$ (II) to $\mathrm{Cu}$ (I) form transiently, as evidenced by the Bader charge analysis. ${ }^{92-94}$ Indeed, upon change of state, one notes an increase in the metallic valence electron index; in the current formalism, this is enough to 


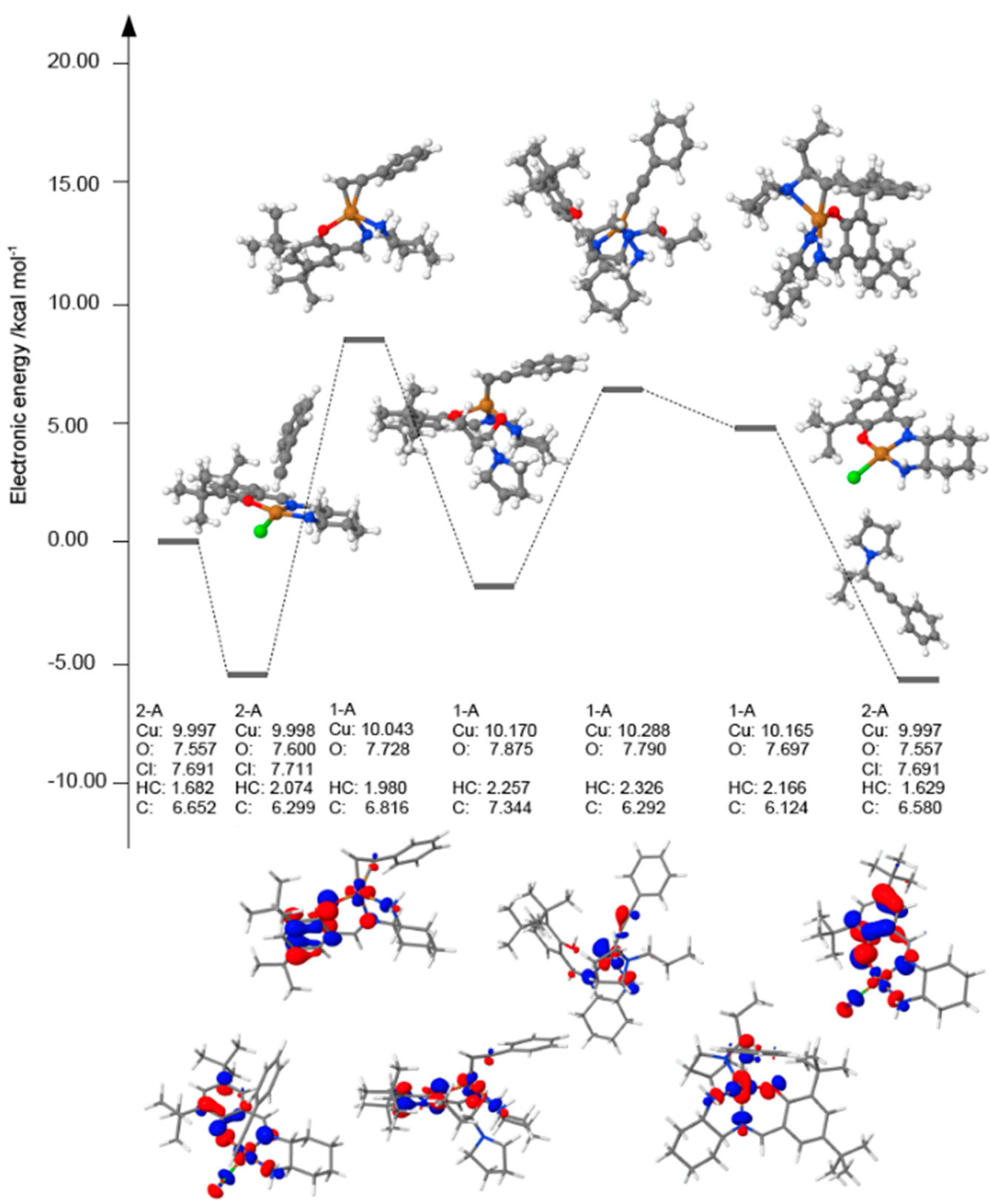

Figure 7. Proposed reaction profile for the $\mathrm{Cu}(\mathrm{II})$-promoted $\mathrm{A}^{3}$ coupling: total electronic energies, electronic state, highest occupied molecular orbitals, and Bader charge analysis.

indicate a change of oxidation state. ${ }^{95,96}$ The change would not have taken place if the center had not been $\mathrm{Cu}$ (II). Second, one could ascribe the facile capture of the reactants to the charge dynamics lability provided by the ligands as explained above; indeed, a closer inspection of the SOMOs and HOMOs indicate the permanent involvement of the metallic $d$ manifolds and, surprisingly, both the ring systems of the ligand and the chlorine. Given the complexity of the reaction, notably the involvement of noncovalent interactions and change of spin-state, the inclusion of both electronic and vibrational entropy contributions in terms of calculations would be biased. Hence, we report the reaction profile in terms of the total electronic energies only, which in our opinion, fits our purpose and the scope of the manuscript. Lastly, both the isotropic Fermi contact couplings and the eigenvalues from the diagonalization of the spin dipole couplings tensor (data not shown) indicate some unpaired electron-nuclear coupling in the oxygen, further validating the experimental results.

\section{CONCLUSIONS}

We have synthesized and characterized a $\mathrm{Cu}$ (II) complex that can activate alkynes at room temperature without base or additives with very low loadings in only $16 \mathrm{~h}$. To the best of our knowledge, the present unconventional protocol is the first example of an $\mathrm{A}^{3}$ coupling incorporating such a time efficient $\mathrm{Cu}$ (II) component. Vital to this success is the use of (i) the asymmetric tridentate ligand, which matches the coordination geometry of the metal center, (ii) weakly binding anions that prevent the formation of other, possible catalytically inactive, species, (iii) a phenoxido moiety that triggers the radical formation, and (iv) unsaturated heteroatoms on the organic framework that accommodate the acetylenic proton during the activation process. Thus, the appropriate ligand design allowed 
us to achieve an exceptional $\mathrm{Cu}$ (II) alkyne activation process and develop an environmental friendly catalytic protocol applicable for synthesizing propargylamines in high yields. $\mathrm{EPR}, \mathrm{CV}, \mathrm{IR}$, and DFT studies shed light on this peculiar $\mathrm{C}-\mathrm{H}$ activation process and our future efforts will focus on catalyst development, notably chiral versions, and their applicability to other organic transformations and asymmetric syntheses relevant to the late-stage elaboration of pharmaceutically valuable scaffolds.

\section{ASSOCIATED CONTENT}

Supporting Information

The Supporting Information is available free of charge at https://pubs.acs.org/doi/10.1021/jacsau.1c00310.

X-ray data for compounds 1 and 6 (CIF)

TG, UV-vis, IR, EPR, and CV data, Cartesian coordinates, copies of ${ }^{1} \mathrm{H}$ and ${ }^{13} \mathrm{C}$ NMR and HRMS of organic compounds (PDF)

\section{AUTHOR INFORMATION}

\section{Corresponding Authors}

George E. Kostakis - Department of Chemistry, School of Life Sciences, University of Sussex, Brighton BN1 9QJ, U.K.; ○ orcid.org/0000-0002-4316-4369; Email: g.kostakis@ sussex.ac.uk

John Spencer - Department of Chemistry, School of Life Sciences, University of Sussex, Brighton BN1 9QJ, U.K.; ○ orcid.org/0000-0001-5231-8836; Email: j.spencer@ sussex.ac.uk

Alfredo Vargas - Department of Chemistry, School of Life Sciences, University of Sussex, Brighton BN1 9QJ, U.K.; (1) orcid.org/0000-0001-7491-791X;

Email: alfredo.vargas@sussex.ac.uk

\section{Authors}

Jack Devonport - Department of Chemistry, School of Life Sciences, University of Sussex, Brighton BN1 9QJ, U.K.

Lauren Sully - Department of Chemistry, School of Life Sciences, University of Sussex, Brighton BN1 9QJ, U.K.

Athanassios K. Boudalis - Institut de Chimie de Strasbourg (UMR 7177, CNRS-Unistra), Université de Strasbourg, F67081 Strasbourg, France; Université de Strasbourg, CNRS, Institut de Physique et Chimie des Matériaux de Strasbourg (IPCMS), UMR 7504, F-67000 Strasbourg, France; (1) orcid.org/0000-0002-8797-1170

Storm Hassell-Hart - Department of Chemistry, School of Life Sciences, University of Sussex, Brighton BN1 9QJ, U.K.

Matthew C. Leech - School of Science, Department of Pharmaceutical Chemical and Environmental Sciences, University of Greenwich, Chatham Maritime ME4 4TB, U.K.; $\odot$ orcid.org/0000-0003-3524-2897

Kevin Lam - School of Science, Department of Pharmaceutical Chemical and Environmental Sciences, University of Greenwich, Chatham Maritime ME4 4TB, U.K.; (1) orcid.org/0000-0003-1481-9212

Alaa Abdul-Sada - Department of Chemistry, School of Life Sciences, University of Sussex, Brighton BN1 9QJ, U.K.

Graham J. Tizzard - UK National Crystallography Service, Chemistry, University of Southampton, Southampton SO1 71BJ, U.K.

Simon J. Coles - UK National Crystallography Service, Chemistry, University of Southampton, Southampton SO1
71BJ, U.K.; Present Address: Sussex Drug Discovery Centre School of Life Sciences University of Sussex Falmer, Brighton BN1 9QG, U.K; ㅈorcid.org/00000001-8414-9272

Complete contact information is available at: https://pubs.acs.org/10.1021/jacsau.1c00310

\section{Author Contributions}

All authors contributed to writing the manuscript and approved its final version. G.E.K. devised the project with critical input and comments from J.S. and A.V. J.D. synthesized the ligand and the complex and performed and evaluated, with G.E.K., the catalytic experiments. S.H.H. synthesized and characterized compounds $\mathbf{2 q}$ and 2 r. M.C.L. and K.L. performed the cyclic voltammetry studies. A.K.B. performed the EPR studies. G.J.T. and S.J.C. performed the crystallographic studies. A.A.S. performed the MS analysis. L.S. and A.V. performed the theoretical calculations.

Notes

The authors declare no competing financial interest. All data supporting this study is provided as supplementary information accompanying this paper. Crystal structures are available from the Cambridge Crystallographic Data Centre at [https://www.ccdc.cam.ac.uk/structures/].

\section{ACKNOWLEDGMENTS}

G.E.K. and J.S. received funding from the School of Life Sciences, the University of Sussex (J.D. Ph.D. fellowship). S.H.H. and J.S. were funded by the EPSRC (EP/P026990/1). We thank the EPSRC UK National Crystallography Service at the University of Southampton ${ }^{97}$ and Prof. Philippe Turek and Dr. Samuel Dagorne for access to the EPR spectrometer and glovebox, respectively, and Dr. Bertrand Vileno and Dr. Nolwenn Le Breton for helpful discussions. We thank Dr. David Smith for helpful discussions. We thank Dr. Nikolaos Tsoureas for accessing and help with the in situ IR studies.

\section{REFERENCES}

(1) Trammell, R.; Rajabimoghadam, K.; Garcia-Bosch, I. CopperPromoted Functionalization of Organic Molecules: From Biologically Relevant $\mathrm{Cu} / \mathrm{O}_{2}$ Model Systems to Organometallic Transformations. Chem. Rev. 2019, 119 (4), 2954-3031.

(2) Bhunia, S.; Pawar, G. G.; Kumar, S. V.; Jiang, Y.; Ma, D. Selected Copper-Based Reactions for $\mathrm{C}-\mathrm{N}, \mathrm{C}-\mathrm{O}, \mathrm{C}-\mathrm{S}$, and $\mathrm{C}-\mathrm{C}$ Bond Formation. Angew. Chem., Int. Ed. 2017, 56 (51), 16136-16179.

(3) Guo, X.-X.; Gu, D.-W.; Wu, Z.; Zhang, W. Copper-Catalyzed C$\mathrm{H}$ Functionalization Reactions: Efficient Synthesis of Heterocycles. Chem. Rev. 2015, 115 (3), 1622-1651.

(4) McCann, S. D.; Stahl, S. S. Copper-Catalyzed Aerobic Oxidations of Organic Molecules: Pathways for Two-Electron Oxidation with a Four-Electron Oxidant and a One-Electron RedoxActive Catalyst. Acc. Chem. Res. 2015, 48 (6), 1756-1766.

(5) Allen, S. E.; Walvoord, R. R.; Padilla-Salinas, R.; Kozlowski, M. C. Aerobic Copper-Catalyzed Organic Reactions. Chem. Rev. 2013, 113 (8), 6234-6458.

(6) Su, L.; Dong, J.; Liu, L.; Sun, M.; Qiu, R.; Zhou, Y.; Yin, S. F. Copper Catalysis for Selective Heterocoupling of Terminal Alkynes. J. Am. Chem. Soc. 2016, 138 (38), 12348-12351.

(7) Yao, B.; Wang, D. X.; Huang, Z. T.; Wang, M. X. Roomerature Aerobic Formation of a Stable Aryl-Cu(III) Complex and Its Reactions with Nucleophiles: Highly Efficient and Diverse Arene C$\mathrm{H}$ Functionalizations of Azacalix[1]Arene[3] Pyridine. Chem. Commun. 2009, 2899-2901. 
(8) Lang, H.; Jakob, A.; Milde, B. Copper(I) Alkyne and Alkynide Complexes. Organometallics 2012, 31 (22), 7661-7693.

(9) Lin, W.; Cao, T.; Fan, W.; Han, Y.; Kuang, J.; Luo, H.; Miao, B.; Tang, X.; Yu, Q.; Yuan, W.; Zhang, J.; Zhu, C.; Ma, S. Enantioselective Double Manipulation of Tetrahydroisoquinolines with Terminal Alkynes and Aldehydes under Copper(I) Catalysis. Angew. Chem., Int. Ed. 2014, 53 (1), 277-281.

(10) Yoshikai, N.; Nakamura, E. Mechanisms of Nucleophilic Organocopper(I) Reactions. Chem. Rev. 2012, 112 (4), 2339-2372.

(11) Zhang, S.; Zhao, L. A Merged Copper(I/II) Cluster Isolated from Glaser Coupling. Nat. Commun. 2019, 10, 4848.

(12) Ziegler, M. S.; Lakshmi, K. V.; Tilley, T. D. Dicopper $\mathrm{Cu}(\mathrm{I}) \mathrm{Cu}(\mathrm{I})$ and $\mathrm{Cu}(\mathrm{I}) \mathrm{Cu}(\mathrm{II})$ Complexes in Copper-Catalyzed Azide-Alkyne Cycloaddition. J. Am. Chem. Soc. 2017, 139 (15), 5378-5386.

(13) Bai, R.; Zhang, G.; Yi, H.; Huang, Z.; Qi, X.; Liu, C.; Miller, J. T.; Kropf, A. J.; Bunel, E. E.; Lan, Y.; Lei, A. Cu(II)-Cu(I) Synergistic Cooperation to Lead the Alkyne C-H Activation. J. Am. Chem. Soc. 2014, 136 (48), 16760-16763.

(14) Zhang, G.; Yi, H.; Zhang, G.; Deng, Y.; Bai, R.; Zhang, H.; Miller, J. T.; Kropf, A. J.; Bunel, E. E.; Lei, A. Direct Observation of Reduction of $\mathrm{Cu}(\mathrm{II})$ to $\mathrm{Cu}(\mathrm{I})$ by Terminal Alkynes. J. Am. Chem. Soc. 2014, 136 (3), 924-926.

(15) Zhu, X.; Chiba, S. Copper-Catalyzed Oxidative CarbonHeteroatom Bond Formation: A Recent Update. Chem. Soc. Rev. 2016, 45 (16), 4504-4523.

(16) Bakhoda, A.; Okoromoba, O. E.; Greene, C.; Raghibi Boroujeni, M.; Bertke, J. A.; Warren, T. H. A Three Coordinate Copper(II) Alkynyl Complex in C-C Bond Formation: The Sesquicentennial of the Glaser Coupling. J. Am. Chem. Soc. 2020, 142 (43), 18483-18490.

(17) Kundu, S.; Greene, C.; Williams, K. D.; Salvador, T. K.; Bertke, J. A.; Cundari, T. R.; Warren, T. H. Three-Coordinate Copper(II) Aryls: Key Intermediates in C-O Bond Formation. J. Am. Chem. Soc. 2017, 139 (27), 9112-9115.

(18) Cao, Y. X.; Dong, X. Y.; Yang, J.; Jiang, S. P.; Zhou, S.; Li, Z. L.; Chen, G. Q.; Liu, X. Y. A Copper-Catalyzed Sonogashira Coupling Reaction of Diverse Activated Alkyl Halides with Terminal Alkynes Under Ambient Conditions. Adv. Synth. Catal. 2020, 362 (11), 22802284

(19) Zhang, Q.; Wang, T.; Zhang, X.; Tong, S.; Wu, Y. D.; Wang, M. $\mathrm{X}$. Radical Reactivity, Catalysis, and Reaction Mechanism of Arylcopper(II) Compounds: The Missing Link in Organocopper Chemistry. J. Am. Chem. Soc. 2019, 141 (45), 18341-18348.

(20) Loukopoulos, E.; Kallitsakis, M.; Tsoureas, N.; Abdul-Sada, A.; Chilton, N. F.; Lykakis, I. N.; Kostakis, G. E. Cu(II) Coordination Polymers as Vehicles in the $\mathrm{A}^{3}$ Coupling. Inorg. Chem. 2017, 56 (9), 4898-4910.

(21) Kallitsakis, M.; Loukopoulos, E.; Abdul-Sada, A.; Tizzard, G. J.; Coles, S. J.; Kostakis, G. E.; Lykakis, I. N. A Copper-BenzotriazoleBased Coordination Polymer Catalyzes the Efficient One-Pot Synthesis of ( $N^{\prime}$-Substituted)-Hydrazo-4-Aryl-1,4-Dihydropyridines from Azines. Adv. Synth. Catal. 2017, 359 (1), 138-145.

(22) Loukopoulos, E.; Abdul-Sada, A.; Csire, G.; Kallay, C.; Brookfield, A.; Tizzard, G. J.; Coles, S.; Lykakis, I.; Kostakis, G. E. Copper(II)-Benzotriazole Coordination Compounds in Click Chemistry: A Diagnostic Reactivity Study. Dalton Trans. 2018, 47, 1049110508.

(23) Sampani, S. I.; Zdorichenko, V.; Danopoulou, M.; Leech, M. C.; Lam, K.; Abdul-Sada, A.; Cox, B.; Tizzard, G. J.; Coles, S. J.; Tsipis, A.; Kostakis, G. E. Shedding Light on the Use of $\mathrm{Cu}(\mathrm{II})$-Salen Complexes in the $\mathrm{A}^{3}$ Coupling Reaction. Dalton Trans. 2020, 49 (2), 289-299.

(24) Sampani, S. I.; Zdorichenko, V.; Devonport, J.; Rossini, G.; Leech, M. C.; Lam, K.; Cox, B.; Abdul-Sada, A.; Vargas, A.; Kostakis, G. E. Structural and Electronic Control of 1-(2-pyridyl)Benzotriazole Bidentate Ligand in Copper Chemistry with Application to Catalysis in the A3 Coupling Reaction. Chem. - Eur. J. 2021, 27 (13), 43944400 .
(25) Wang, Y.; DuBois, J. L.; Hedman, B.; Hodgson, K. O.; Stack, T. D. P. Catalytic Galactose Oxidase Models: Biomimetic $\mathrm{Cu}(\mathrm{II})$ Phenoxyl-Radical Reactivity. Science 1998, 279, 537-540.

(26) Wang, Y.; Stack, T. D. P. Galactose Oxidase Model Complexes: Catalytic Reactivities. J. Am. Chem. Soc. 1996, 118 (51), 1309713098.

(27) Oshita, H.; Shimazaki, Y. Recent Advances in One-ElectronOxidized CuII-Diphenoxide Complexes as Models of Galactose Oxidase: Importance of the Structural Flexibility in the Active Site. Chem. - Eur. J. 2020, 26 (38), 8324-8340.

(28) Jung, H. J.; Yu, I.; Nyamayaro, K.; Mehrkhodavandi, P. IndiumCatalyzed Block Copolymerization of Lactide and Methyl Methacrylate by Sequential Addition. ACS Catal. 2020, 10 (11), 64886496.

(29) Kavanagh, S. E.; Gilheany, D. G. Harnessing the Power of the Asymmetric Grignard Synthesis of Tertiary Alcohols: Ligand Development and Improved Scope Exemplified by One-Step Gossonorol Synthesis. Org. Lett. 2020, 22 (21), 8198-8203.

(30) Samuelsen, S. V.; Santilli, C.; Ahlquist, M. S. G.; Madsen, R. Development and Mechanistic Investigation of the Manganese(III) Salen-Catalyzed Dehydrogenation of Alcohols. Chem. Sci. 2019, 10 (4), 1150-1157.

(31) Halcrow, M. A. Jahn-Teller Distortions in Transition Metal Compounds, and Their Importance in Functional Molecular and Inorganic Materials. Chem. Soc. Rev. 2013, 42 (4), 1784-1795.

(32) Tynan, E.; Jensen, P.; Lees, A. C.; Moubaraki, B.; Murray, K. S.; Kruger, P. E. The Role of Acid in the Formation of Hydrogen-Bonded Networks Featuring 4,4'-Dicarboxy-2,2'-Bipyridine ( $\left.\mathrm{H}_{2} \mathrm{dcbp}\right)$ : Synthesis, Structural and Magnetic Characterisation of $\left\{\left[\mathrm{Cu}\left(\mathrm{H}_{2} \mathrm{dcbp}\right)\right.\right.$ $\left.\left.\mathrm{Cl}_{2}\right] \cdot \mathrm{H}_{2} \mathrm{O}\right\}_{2}$ and $\left[\mathrm{Cu}\left(\mathrm{H}_{2} \mathrm{dcbp}\right)\left(\mathrm{NO}_{3}\right)_{2}\left(\mathrm{H}_{2} \mathrm{O}\right)\right]$. CrystEngComm 2005, 7 (13), 90-95.

(33) Allen, J. J.; Hamilton, C. E.; Barron, A. R. Synthesis and Characterization of Aryl Substituted Bis(2-Pyridyl)Amines and Their Copper Olefin Complexes: Investigation of Remote Steric Control over Olefin Binding. Dalton Trans. 2010, 39 (47), 11451-11468.

(34) Kostakis, G. E.; Nordlander, E.; Haukka, M.; Plakatouras, J. C. Di- $\mu$-Chloro-Bis[(2,2-Bipyridine)Chlorocopper(II)]. Acta Crystallogr., Sect. E: Struct. Rep. Online 2006, 62 (1), m77-m79.

(35) Kunert, R.; Philouze, C.; Berthiol, F.; Jarjayes, O.; Storr, T.; Thomas, F. Distorted Copper(II) Radicals with Sterically Hindered Salens: Electronic Structure and Aerobic Oxidation of Alcohols. Dalton Trans. 2020, 49 (37), 12990-13002.

(36) Kanso, H.; Clarke, R. M.; Kochem, A.; Arora, H.; Philouze, C.; Jarjayes, O.; Storr, T.; Thomas, F. Effect of Distortions on the Geometric and Electronic Structures of One-Electron Oxidized Vanadium(IV), Copper(II), and Cobalt(II)/(III) Salen Complexes. Inorg. Chem. 2020, 59 (7), 5133-5148.

(37) Taylor, M. K.; Reglinski, J.; Berlouis, L. E. A.; Kennedy, A. R. The Effect of Donor Groups and Geometry on the Redox Potential of Copper Schiff Base Complexes. Inorg. Chim. Acta 2006, 359 (8), $2455-2464$.

(38) Das, D.; Mandal, A.; Sarkar, A.; Adhikary, A.; Samanta, D. Structure and Synthesis of Copper Based Schiff Base and Reduced Schiff Base Complex: A Combined Experimental and Theoretical Investigation of Biomimetic Catalytic Activity. Dalton Trans. 2020, 49 (43), 15461-15472.

(39) Song, S. E.; Nguyen, Q. T.; Yu, J. J.; Lee, H. I.; Jeong, J. H. Synthesis and Characterisation of $\mathrm{Cu}(\mathrm{II})$ Complexes Bearing N,N'$\operatorname{Di}($ Methoxybenzyl)-(R,R)-1,2-Diaminocyclohexane as Catalysts for the Asymmetric Nitroaldol Reaction. Polyhedron 2014, 67, 264-269. (40) Zhang, G.; Yashima, E.; Woggon, W. D. Versatile Supramolecular Copper(II) Complexes for Henry and Aza-Henry Reactions. Adv. Synth. Catal. 2009, 351 (9), 1255-1262.

(41) Mandal, S.; Mukherjee, J.; Lloret, F.; Mukherjee, R. Modeling Tyrosinase and Catecholase Activity Using New M-Xylyl-Based Ligands with Bidentate Alkylamine Terminal Coordination. Inorg. Chem. 2012, 51 (24), 13148-13161.

(42) Biswas, A.; Drew, M. G. B.; Song, Y.; Ghosh, A. Effect of Anionic Co-Ligands on Structure and Magnetic Coupling of $\operatorname{Bis}(\mu$ - 
Phenoxo)-Bridged Dinuclear Copper(II) Complexes. Inorg. Chim. Acta 2011, 376 (1), 422-427.

(43) Orio, M.; Jarjayes, O.; Kanso, H.; Philouze, C.; Neese, F.; Thomas, F. X-Ray Structures of Copper(II) and Nickel(II) Radical Salen Complexes: The Preference of Galactose Oxidase for Copper(II). Angew. Chem., Int. Ed. 2010, 49 (29), 4989-4992.

(44) Böttcher, A.; Elias, H.; Jäger, E. G.; Langfelderova, H.; Mazur, M.; Müller, L.; Paulus, H.; Pelikan, P.; Rudolph, M.; Valko, M. Comparative Study on the Coordination Chemistry of Cobalt(II), Nickel(II), and Copper(II) with Derivatives of Salen and Tetrahydrosalen: Metal-Catalyzed Oxidative Dehydrogenation of the C-N Bond in Coordinated Tetrahydrosalen. Inorg. Chem. 1993, 32 (19), 4131-4138.

(45) Pasini, A.; Bernini, E.; Scaglia, M.; De Santis, G. Studies on the Oxidation of CuII Complexes of Quadridentate Schiff Bases Derived from Salicylaldehyde or Ortho-Aminophenol. Polyhedron 1996, 15 (24), 4461-4467.

(46) Chiang, L.; Herasymchuk, K.; Thomas, F.; Storr, T. Influence of Electron-Withdrawing Substituents on the Electronic Structure of Oxidized $\mathrm{Ni}$ and $\mathrm{Cu}$ Salen Complexes. Inorg. Chem. 2015, 54 (12), 5970-5980.

(47) Adão, P.; Barroso, S.; Avecilla, F.; Oliveira, M. C.; Pessoa, J. C. CuII-Salan Compounds: Synthesis, Characterization and Evaluation of Their Potential as Oxidation Catalysts. J. Organomet. Chem. 2014, $760,212-223$.

(48) Chiang, L.; Wasinger, E. C.; Shimazaki, Y.; Young, V.; Storr, T.; Stack, T. D. P. Electronic Structure and Reactivity Studies of a Nonsymmetric One-Electron Oxidized CuII Bis-Phenoxide Complex. Inorg. Chim. Acta 2018, 481, 151-158.

(49) Biswas, A.; Das, L. K.; Drew, M. G. B.; Diaz, C.; Ghosh, A. Insertion of a Hydroxido Bridge into a Diphenoxido Dinuclear Copper(II) Complex: Drastic Change of the Magnetic Property from Strong Antiferromagnetic to Ferromagnetic and Enhancement in the Catecholase Activity. Inorg. Chem. 2012, 51 (19), 10111-10121.

(50) Golchoubian, H.; Fateh, D. S.; Bruno, G.; Rudbari, H. A. Homo and Heterodinuclear Complexes Derived from Unsymmetrical Macrocyclic Ligands with Two Coordination Sites: Removal of a Pendant Arm and Migration of Copper Ion upon Cyclization. J. Coord. Chem. 2012, 65 (11), 1970-1991.

(51) Ghorai, S.; Sarmah, A.; Roy, R. K.; Tiwari, A.; Mukherjee, C. Effect of Geometrical Distortion on the Electronic Structure: Synthesis and Characterization of Monoradical-Coordinated Mononuclear $\mathrm{Cu}(\mathrm{II})$ Complexes. Inorg. Chem. 2016, 55 (4), 1370-1380.

(52) De Bellefeuille, D.; Orio, M.; Barra, A. L.; Aukauloo, A.; Journaux, Y.; Philouze, C.; Ottenwaelder, X.; Thomas, F. Redox Noninnocence of the Bridge in Copper(II) Salophen and Bis(Oxamato) Complexes. Inorg. Chem. 2015, 54 (18), 9013-9026.

(53) Kochem, A.; Jarjayes, O.; Baptiste, B.; Philouze, C.; Vezin, H.; Tsukidate, K.; Tani, F.; Orio, M.; Shimazaki, Y.; Thomas, F. OneElectron Oxidized Copper(II) Salophen Complexes: Phenoxyl versus Diiminobenzene Radical Species. Chem. - Eur. J. 2012, 18 (4), 10681072.

(54) Thomas, F.; Jarjayes, O.; Duboc, C.; Philouze, C.; Saint-Aman, E.; Pierre, J. L. Intramolecularly Hydrogen-Bonded versus Copper(II) Coordinated Mono- and Bis-Phenoxyl Radicals. Dalton Trans. 2004, $2662-2669$.

(55) Pratt, R. C.; Stack, T. D. P. Intramolecular Charge Transfer and Biomimetic Reaction Kinetics in Galactose Oxidase Model Complexes. J. Am. Chem. Soc. 2003, 125 (29), 8716-8717.

(56) Lyons, C. T.; Stack, T. D. P. Recent Advances in Phenoxyl Radical Complexes of Salen-Type Ligands as Mixed-Valent Galactose Oxidase Models. Coord. Chem. Rev. 2013, 257 (2), 528-540.

(57) Storr, T.; Verma, P.; Pratt, R. C.; Wasinger, E. C.; Shimazaki, Y.; Stack, T. D. P. Defining the Electronic and Geometric Structure of One-Electron Oxidized Copper-Bis-Phenoxide Complexes. J. Am. Chem. Soc. 2008, 130 (46), 15448-15459.

(58) Mathivathanan, L.; Rogez, G.; Ben Amor, N.; Robert, V.; Raptis, R. G.; Boudalis, A. K. Origin of Ferromagnetism and Magnetic
Anisotropy in a Family of Copper(II) Triangles. Chem. - Eur. J. 2020, 26 (56), 12769-12784.

(59) Dou, X. Y.; Shuai, Q.; He, L. N.; Li, C. J. Copper(II) TriflateCatalyzed Three-Component Coupling of Aldehydes, Alkynes and Carbamates. Adv. Synth. Catal. 2010, 352 (14-15), 2437-2440.

(60) Wei, C.; Li, Z.; Li, C. J. The First Silver-Catalyzed ThreeComponent Coupling of Aldehyde, Alkyne, and Amine. Org. Lett. 2003, 5 (23), 4473-4475.

(61) Bisai, V.; Suneja, A.; Singh, V. K. Asymmetric Alkynylation/ Lactamization Cascade: An Expeditious Entry to Enantiomerically Enriched Isoindolinones. Angew. Chem., Int. Ed. 2014, 53 (40), 10737-10741.

(62) Zhang, Y.; Huang, L.; Li, X.; Wang, L.; Feng, H. Chemo- and Diastereoselective Synthesis of N-Propargyl Oxazolidines through a Copper-Catalyzed Domino A3 Reaction. J. Org. Chem. 2019, 84 (9), 5046-5055.

(63) Liu, C.; Wang, G.; Wang, Y.; Pereshivko, O. P.; Peshkov, V. A. Copper-Catalyzed Reaction of Secondary Propargylamines with Ethyl Buta-2,3-Dienoate for the Synthesis of 1,6-Dihydropyridines. Eur. J. Org. Chem. 2019, 2019 (10), 1981-1985.

(64) Singh, P.; Adolfsson, D. E.; Ådén, J.; Cairns, A. G.; Bartens, C.; Brännström, K.; Olofsson, A.; Almqvist, F. Pyridine-Fused 2Pyridones via Povarov and $\mathrm{A}^{3}$ Reactions: Rapid Generation of Highly Functionalized Tricyclic Heterocycles Capable of Amyloid Fibril Binding. J. Org. Chem. 2019, 84 (7), 3887-3903.

(65) Carmona, R. C.; Wendler, E. P.; Sakae, G. H.; Comassetoa, J. V.; Santos, A. A. D. A A $^{3}$-Coupling Reaction as a Strategy towards the Synthesis of Alkaloids. J. Braz. Chem. Soc. 2014, 26 (1), 117-123.

(66) Zhou, S.; Tong, R. Three-Step Catalytic Asymmetric Total Syntheses of 13-Methyltetrahydroprotoberberine Alkaloids. Org. Lett. 2017, 19 (7), 1594-1597.

(67) Gommermann, N.; Knochel, P. Practical Highly Enantioselective Synthesis of Terminal Propargylamines. An Expeditious Synthesis of (S)-(+)-Coniine. Chem. Commun. 2004, No. 20, 2324-2325.

(68) Peewasan, K.; Merkel, M. P.; Fuhr, O.; Anson, C. E.; Powell, A. K. A Multifunctional Use of Bis(Methylene)Bis(5-Bromo-2-Hydroxyl Salicyloylhydrazone): From Metal Sensing to Ambient Catalysis of $\mathrm{A}^{3}$ Coupling Reactions. RSC Adv. 2020, 10 (67), 40739-40744.

(69) Agrahari, B.; Layek, S.; Ganguly, R.; Pathak, D. D. Synthesis and Crystal Structures of Salen-Type $\mathrm{Cu}(\mathrm{II})$ and $\mathrm{Ni}$ (II) Schiff Base Complexes: Application in [3 + 2]-Cycloaddition and A3-Coupling Reactions. New J. Chem. 2018, 42 (16), 13754-13762.

(70) Yuzpe, A. A.; Lancee, W. J. Ethinylestradiol and Dl-Norgestrel as a Postcoital Contraceptive. Fertil. Steril. 1977, 28 (9), 932-936.

(71) Queiroz, T. M.; Orozco, E. V. M.; Silva, V. R.; Santos, L. S.; Soares, M. B. P.; Bezerra, D. P.; Porto, A. L. M. Semi-Synthesis of $\beta$ Keto-1,2,3-Triazole Derivatives from Ethinylestradiol and Evaluation of the Cytotoxic Activity. Heliyon 2019, 5 (9), e02408.

(72) Liu, G.; Wang, W.; Lin, J.; Li, K.; Lv, G.; Zhao, X.; Wang, S.; Luo, S.; Qiu, L. Kit-like 18F-Labeling of an Estradiol Derivative as a Potential PET Imaging Agent for Estrogen Receptor-Positive Breast Cancer. J. Radioanal. Nucl. Chem. 2017, 312 (3), 599-607.

(73) Tyler, D. S.; Vappiani, J.; Cañeque, T.; Lam, E. Y. N.; Ward, A.; Gilan, O.; Chan, Y.-C.; Hienzsch, A.; Rutkowska, A.; Werner, T.; Wagner, A. J.; Lugo, D.; Gregory, R.; Ramirez Molina, C.; Garton, N.; Wellaway, C. R.; Jackson, S.; MacPherson, L.; Figueiredo, M.; Stolzenburg, S.; Bell, C. C.; House, C.; Dawson, S.-J.; Hawkins, E. D.; Drewes, G.; Prinjha, R. K.; Rodriguez, R.; Grandi, P.; Dawson, M. A. Click Chemistry Enables Preclinical Evaluation of Targeted Epigenetic Therapies. Science 2017, 356 (6345), 1397-1401.

(74) Lovering, F.; Bikker, J.; Humblet, C. Escape from Flatland: Increasing Saturation as an Approach to Improving Clinical Success. J. Med. Chem. 2009, 52 (21), 6752-6756.

(75) Xu, Y.; Gu, Y.; Qian, S. Y. An Advanced Electron Spin Resonance (ESR) Spin-Trapping and LC/(ESR)/MS Technique for the Study of Lipid Peroxidation. Int. J. Mol. Sci. 2012, 13 (11), $14648-14666$. 
(76) Asami, K.; Takashina, A.; Kobayashi, M.; Iwatsuki, S.; Yajima, T.; Kochem, A.; Van Gastel, M.; Tani, F.; Kohzuma, T.; Thomas, F.; Shimazaki, Y. Characterization of One-Electron Oxidized Copper(II)Salophen-Type Complexes; Effects of Electronic and Geometrical Structures on Reactivities. Dalton Trans. 2014, 43 (5), 2283-2293.

(77) Monzani, E.; Quinti, L.; Perotti, A.; Casella, L.; Gullotti, M.; Randaccio, L.; Geremia, S.; Nardin, G.; Faleschini, P.; Tabbì, G. Tyrosinase Models. Synthesis, Structure, Catechol Oxidase Activity, and Phenol Monooxygenase Activity of a Dinuclear Copper Complex Derived from a Triamino Pentabenzimidazole Ligand. Inorg. Chem. 1998, 37 (3), 553-562.

(78) Sprakel, V. S. I.; Feiters, M. C.; Meyer-Klaucke, W.; Klopstra, M.; Brinksma, J.; Feringa, B. L.; Karlin, K. D.; Nolte, R. J. M. Oxygen Binding and Activation by the Complexes of PY2- and TPAAppended Diphenylglycoluril Receptors with Copper and Other Metals. Dalton Trans. 2005, No. 21, 3522-3534.

(79) Karlin, K. D.; Cruse, R. W.; Gultneh, Y.; Farooq, A.; Hayes, J. C.; Zubieta, J. Dioxygen-Copper Reactivity. Reversible Binding of $\mathrm{O}_{2}$ and CO to a Phenoxo-Bridged Dicopper(I) Complex. J. Am. Chem. Soc. 1987, 109 (9), 2668-2679.

(80) Battaini, G.; Monzani, E.; Perotti, A.; Para, C.; Casella, L.; Santagostini, L.; Gullotti, M.; Dillinger, R.; Näther, C.; Tuczek, F. A Double Arene Hydroxylation Mediated by Dicopper(II)-Hydroperoxide Species. J. Am. Chem. Soc. 2003, 125 (14), 4185-4198.

(81) Ryland, B. L.; Stahl, S. S. Practical Aerobic Oxidations of Alcohols and Amines with Homogeneous Copper/TEMPO and Related Catalyst Systems. Angew. Chem., Int. Ed. 2014, 53 (34), 8824-8838.

(82) Seidel, D. The Redox- $\mathrm{A}^{3}$ Reaction. Org. Chem. Front. 2014, 1 (4), 426-429.

(83) Fässler, R.; Tomooka, C. S.; Frantz, D. E.; Carreira, E. M. Infrared Spectroscopic Investigations on the Metallation of Terminal Alkynes by $\mathrm{Zn}(\mathrm{OTf})_{2}$. Proc. Natl. Acad. Sci. U. S. A. 2004, 101 (16), $5843-5845$.

(84) Létinois-Halbes, U.; Pale, P.; Berger, S. Ag NMR as a Tool for Mechanistic Studies of Ag-Catalyzed Reactions: Evidence for in Situ Formation of Alkyn-1-Yl Silver from Alkynes and Silver Salts. J. Org. Chem. 2005, 70 (23), 9185-9190.

(85) Liu, S.; Pedersen, L. G. Estimation of Molecular Acidity via Electrostatic Potential at the Nucleus and Valence Natural Atomic Orbitals. J. Phys. Chem. A 2009, 113 (15), 3648-3655.

(86) Liptak, M. D.; Gross, K. C.; Seybold, P. G.; Feldgus, S.; Shields, G. C. Absolute $\mathrm{pK}_{\mathrm{a}}$ Determinations for Substituted Phenols. J. Am. Chem. Soc. 2002, 124 (22), 6421-6427.

(87) Sharma, I.; Kaminski, G. A. Calculating PK a Values for Substituted Phenols and Hydration Energies for Other Compounds with the First-Order Fuzzy-Border Continuum Solvation Model. J. Comput. Chem. 2012, 33 (30), 2388-2399.

(88) Zeng, Y.; Chen, X.; Zhao, D.; Li, H.; Zhang, Y.; Xiao, X. Estimation of $\mathrm{pK}_{\mathrm{a}}$ Values for Carboxylic Acids, Alcohols, Phenols and Amines Using Changes in the Relative Gibbs Free Energy. Fluid Phase Equilib. 2012, 313, 148-155.

(89) Koradin, C.; Polborn, K.; Knochel, P. Enantioselective Synthesis of Propargylamines by Copper-Catalyzed Addition of Alkynes to Enamines. Angew. Chem., Int. Ed. 2002, 41 (14), 25352538.

(90) Liu, Q.; Xu, H.; Li, Y.; Yao, Y.; Zhang, X.; Guo, Y.; Ma, S. Pyrinap Ligands for Enantioselective Syntheses of Amines. Nat. Commun. 2021, 12 (1), 1-10.

(91) Rokade, B. V.; Guiry, P. J. Diastereofacial $\pi$-Stacking as an Approach to Access an Axially Chiral P,N-Ligand for Asymmetric Catalysis. ACS Catal. 2017, 7 (4), 2334-2338.

(92) Tang, W.; Sanville, E.; Henkelman, G. A Grid-Based Bader Analysis Algorithm without Lattice Bias. J. Phys.: Condens. Matter 2009, 21 (8), 084204.

(93) Sanville, E.; Kenny, S. D.; Smith, R.; Henkelman, G. Improved Grid-Based Algorithm for Bader Charge Allocation. J. Comput. Chem. 2007, 28 (5), 899-908.
(94) Henkelman, G.; Arnaldsson, A.; Jónsson, H. A Fast and Robust Algorithm for Bader Decomposition of Charge Density. Comput. Mater. Sci. 2006, 36 (3), 354-360.

(95) Raebiger, H.; Lany, S.; Zunger, A. Charge Self-Regulation upon Changing the Oxidation State of Transition Metals in Insulators. Nature 2008, 453 (7196), 763-766.

(96) Xu, M.; Xiao, P.; Stauffer, S.; Song, J.; Henkelman, G.; Goodenough, J. B. Theoretical and Experimental Study of VanadiumBased Fluorophosphate Cathodes for Rechargeable Batteries. Chem. Mater. 2014, 26 (10), 3089-3097.

(97) Coles, S. J.; Gale, P. A. Changing and Challenging Times for Service Crystallography. Chem. Sci. 2012, 3 (3), 683-689. 